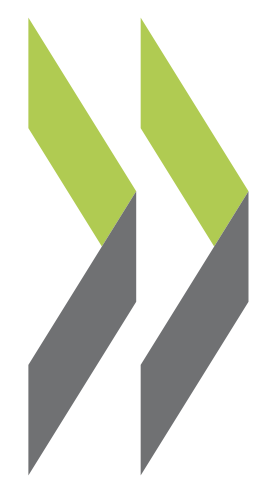

OECD Economics Department Working Papers No. 1683

Welcome to the (digital) jungle: Measuring online platform diffusion
Hélia Costa,

Giuseppe Nicoletti,

Mauro Pisu,

Christina von Rueden 


\section{WELCOME TO THE (DIGITAL) JUNGLE: MEASURING ONLINE PLATFORM DIFFUSION} ECONOMICS DEPARTMENT WORKING PAPERS No. 1683

By Hélia Costa, Giuseppe Nicoletti, Mauro Pisu and Christina von Rueden

OECD Working Papers should not be reported as representing the official views of the OECD or of its member countries. The opinions expressed and arguments employed are those of the author(s).

Authorised for publication by Luiz de Mello, Director, Policy Studies Branch, Economics Department.

All Economics Department Working Papers are available at www.oecd.org/eco/workingpapers 
OECD Working Papers should not be reported as representing the official views of the OECD or of its member countries. The opinions expressed and arguments employed are those of the author(s).

Working Papers describe preliminary results or research in progress by the author(s) and are published to stimulate discussion on a broad range of issues on which the OECD works.

Comments on Working Papers are welcomed, and may be sent to OECD Economics Department, 2 rue André Pascal, 75775 Paris Cedex 16, France, or by e-mail to eco.contact@oecd.org.

All Economics Department Working Papers are available at www.oecd.org/eco/workingpapers.

This document and any map included herein are without prejudice to the status of or sovereignty over any territory, to the delimitation of international frontiers and boundaries and to the name of any territory, city or area.

The statistical data for Israel are supplied by and under the responsibility of the relevant Israeli authorities. The use of such data by the OECD is without prejudice to the status of the Golan Heights, East Jerusalem and Israeli settlements in the West Bank under the terms of international law.

(C) OECD (2021)

You can copy, download or print OECD content for your own use, and you can include excerpts from OECD publications, databases and multimedia products in your own documents, presentations, blogs, websites and teaching materials, provided that suitable acknowledgment of OECD as source and copyright owner is given. All requests for commercial use and translation rights should be submitted to Pubrights@oecd.org 


\section{ABSTRACT / RESUME}

\section{Welcome to the (digital) jungle: measuring online platform diffusion}

Despite the rising importance and economy-wide effects of online platforms, the paucity of cross-country comparable data still hampers understanding of the structural and policy determinants of their diffusion. This study contributes to the understanding of multi-sided online platforms in three main ways. First, we build a harmonised international dataset of online platforms and their use across 43 OECD and G20 countries, covering the 2013-19 period and nine areas of activity. Second, we describe main trends in the use of platforms in the past years, and third, we investigate the structural and policy determinants of online platforms diffusion across countries and over time.

JEL classification codes: C80, M20, O33.

Keywords: Data collection, online platforms, digitalisation.

\section{Bienvenue dans la jungle (numérique): mesurer la diffusion des plateformes numériques}

En dépit de l'importance croissante des plateformes numériques et de leurs effets sur l'ensemble de l'économie, la compréhension des facteurs structurels et des politiques publiques qui favorisent leur diffusion demeure entravée par le manque de données comparables au plan international. La présente étude contribue à la compréhension des plateformes numériques multifaces par trois voies essentiellement. Premièrement, nous établissons un ensemble de données internationales harmonisées sur les plateformes numériques et leur utilisation dans 43 pays de l'OCDE et du G20 et dans neuf secteurs d'activité sur la période 2013-19. Deuxièmement, nous présentons les principales tendances observées au cours des dernières années en matière d'utilisation des plateformes, et troisièmement, nous examinons les facteurs structurels et les politiques publiques influant sur la diffusion des plateformes numériques dans les différents pays et dans le temps.

Codes de classification JEL : C80, M20, 033.

Mots clés: Collecte de données, plateformes numériques, digitalisation. 


\section{Table of contents}

Welcome to the (digital) jungle: measuring online platform diffusion 6

1. Introduction 6

2. Measuring online platform activity 9

3. Online platform diffusion over the past decade: stylised facts 14

3.1. Online platforms' diffusion has been fast and ubiquitous but differs across activity areas 14

3.2. Network and income effects drive online platforms' penetration 17

3.3. Online platforms are increasingly global but specialized in few activities $\quad 19$

3.4. Are platforms getting too big? 22

4. Structural and policy drivers of platform diffusion $\quad 27$

4.1. Platform diffusion depends on both platform and country characteristics 31

$\begin{array}{ll}\text { 5. Conclusion } & 42\end{array}$

References $\quad 43$

Annex A. Additional information on data collection $\quad 49$

Annex B. Regression Analysis $\quad 51$

\section{Tables}

Table 1. Sectors and countries covered in the sample $\quad 12$

Table 2. Dynamics of online platforms traffic by sector $\quad 15$

Table 4. Summary of results on platform diffusion $\quad 31$

$\begin{array}{ll}\text { Table A.1. Platforms across areas of activity } & 49\end{array}$

Table A.2. Classification specifications $\quad 49$

Table B.1. Regression results: Platform diffusion and country characteristics $\quad 51$

Table B.2. Platform traffic and entry and platform characteristics $\quad 52$

Table B.3. Structural policies and country-level traffic $\quad 53$

Table B.4. Platform traffic and concentration $\quad 55$

\section{Figures}

Figure 1. Potential links between platform categories and selected policies $\quad 13$

Figure 2. Online platforms have developed rapidly over the past decade 14

Figure 3. The number of platforms varies across sectors 16

Figure 4. Larger and richer countries tend to have more traffic but less platforms per capita 18

Figure 5. Platform traffic per capita is associated with larger platforms, suggesting the presence of network effects

Figure 6. A minority of global platform generate most of the traffic

Figure 7. Most online platforms operate in just one area of activity 22 
Figure 8. Online platform global traffic concentration varies across areas of activity and has decreased over time

Figure 9. Online platform traffic concentration by sector varies across countries and has also been decreasing over time

Figure 10. Traffic concentration tends to be lower in sectors with more global platforms 26

Figure 11. Taxonomy of variables affecting platforms' diffusion and uptake 28

Figure 12. Platform characteristics and diffusion $\quad 32$

Figure 13. Structural characteristics and platform diffusion $\quad 34$

Figure 14. Quality of institutions and platform diffusion $\quad 38$

Figure 15. Regulation, licensing and platform diffusion $\quad 39$

Figure 16. Regulation of digital services and platform diffusion $\quad 40$

Figure 17. Cross border data transferability affects differently international and local platforms 41

Figure A.1. Classification examples of online platforms 50

\section{Boxes}

Box 1. Selected OECD past and current work on online platforms 8

Box 2. Efforts to better measure digital platforms and the digital economy 10

Box 3. Multi-sided online platforms and network effects 17

Box 4. A bird's-eye view of online platform developments in China 25

Box 5. Selected OECD work on online platforms and competition 27

Box 6. The drivers of platform diffusion: empirical strategy 29 


\title{
Welcome to the (digital) jungle: measuring online platform diffusion
}

\author{
By Hélia Costa, Giuseppe Nicoletti, Mauro Pisu and Christina von Rueden ${ }^{1}$
}

\section{Introduction}

1. Online platforms are one of the key defining features of the ongoing digitalisation process as they are becoming globally ubiquitous. Over the past decade, people and businesses have been increasingly using them to buy and sell services and goods, and for many other purposes such as finding jobs, getting information, and entertainment. Yet, despite their increasing importance in modern economies, the measurement of platform activity in official statistics is still deficient (OECD, 2020[1]). As underlined by the Stigler Committee on Digital Platforms (Zingales and Lancieri, 2019), platforms often refuse to provide independent researchers with the data necessary to evaluate the impact of their activity on the economy and society. As a result, debates on online platforms are mired in a paradoxical situation: though online platforms are adept in collecting and exploiting large quantity of data on users, customers and service providers, public understanding on their operations and impacts is held back by the lack of data.

2. National experiences in gathering data directly from platform companies vary greatly as these are commercially sensitive and raise also privacy related issues. Several countries have taken a proactive approach to covering platforms; for example, the United Kingdom Office for National Statistics identified ("sharing-economy"2) platforms and included these in the Annual Business Survey and the E-commerce survey in 2016. A limitation of this approach is that it relies on platforms having a physical or legal presence in the country. However, the online nature of platforms' business models means that they are often active in countries without having any formal presence there and that they can route and process transactions in multiple ways (OECD, 2019 $\left.{ }_{[2]}\right)$. Work at the OECD, other international organisations and national statistical

\footnotetext{
${ }^{1}$ Corresponding authors: Hélia Costa (helia.costa@oecd.org), Giuseppe Nicoletti (nicolettigiuseppe4@gmail.com), Mauro Pisu (mauro.pisu@oecd.org) and Christina von Rueden (christina.vonrueden@svr-wirtschaft.de). All four authors were in the OECD Economics Department at the time of this work. The authors would like to thank Valentine Millot, Laurence Boone, Luiz de Mello, Alain de Serres, Dan Andrews (all from the OECD Economics Department), Cecilia Jona-Lasinio, Valeria Patella, Silvia Sopranzetti (Italian 2021 G20 Presidency), colleagues from the Centre for Entrepreneurship, SMEs, Regions and Cities, Directorate for Science, Technology, Directorate for Financial and Enterprise Affairs, Directorate for Employment, Labour and Social Affairs, Statistics and Data Directorate, and participants at the G20 Seminar series organised by the Italian G20 Team in preparation to the 2021 G20 Italian Presidency, the OECD applied micro seminar, the Collége de France/Banque de France joint Workshop on Growth, Innovation and Automation, and the University of Minho NIPE seminar for valuable comments. The authors would also like to thank Sarah Michelson Sarfati (also from the OECD Economics Department) for excellent editorial support.
}

2 The sharing economy involves short-term peer-to-peer transactions to share use of idle assets and services or to facilitate collaboration. 
offices is ongoing to define standards, modules and procedures and to collect better data allowing for cross-country comparisons (OECD, 2018[3]; OECD, 2019 $\left.9_{[4]}\right)$.

3. The OECD has been investigating many of these challenges in several work strands and publications (Box 1). A common thread of this work is the need to collect better and more reliable data on the operations of online platforms to better understand the determinants of online platforms' diffusion and their impacts. The OECD's Toolkit for Measuring the Digital Economy (OECD, 2018) warned that current measures of the digital economy are inadequate as, for instance, they do not allow for the measurement of the size and impact of online platforms. Ongoing work at the OECD is tackling these fundamental measurement issues (OECD, 2019[7]).

4. This study contributes to the understanding of online platforms' diffusion in three main ways. First, we build a harmonised international dataset of online platforms across 43 OECD and G20 countries, covering the 2013-19 period and nine areas of activity, including accommodation, business-to-consumer and consumer-to-consumer marketplaces, business-to-business marketplaces, mobile payments, personal services, professional services, restaurant booking, restaurant delivery, and transport. ${ }^{3}$ The focus is on multisided online platforms, defined as those that facilitate interactions between two or more distinct but interdependent sets of users (whether firms or individuals) who interact to exchange goods or services via the Internet. ${ }^{4}$ Websites' traffic (i.e. the estimated number of platform-website visits) is used as a proxy for the diffusion and penetration of platforms covered by this study. While platform websites' traffic is just an approximation of the actual use of and exchanges within platforms, it has the benefit of being consistent across platforms, countries and over time, providing a first attempt to better assess the diffusion of online platforms in relative terms across countries (OECD, 2018[3]).

5. Second, we uncover a number of stylized facts from these data:

- Network effects tend to drive the diffusion and uptake of online platforms across countries, as their activity tends to concentrate in a limited number of large platforms. Larger and richer countries tend to have bigger and fewer online platforms (per inhabitant) than smaller and poorer countries. Thus, as platforms develop, policy makers need to ensure that the benefits stemming from large network effects remain compatible with those from more competition among online platforms.

- Traffic concentration of online platform activity, although high, has been decreasing over time with large variation across countries and activity areas - suggesting that the market power of online platforms is not necessarily impervious to competition. The scale-without-mass feature of online platforms' business models (Brynjolfsson et al., 2007[4]), along with low marginal costs, may allow newer platforms to challenge dominant players in some markets.

- Most online platforms operate in many countries and global platforms account for a large and increasing share of total platforms' traffic. However, global platforms do not appear to contribute to the concentration of online platform activities (measured by website traffic) more than those operating in just a few countries, as local platforms are, on average, large as well.

6. Third, we provide evidence on how the following policies and institutions affect the diffusion of online platforms:

\footnotetext{
3 Data collection for this study builds on the previous OECD report An Introduction to Online Platforms (OECD, $\left.2019_{[11]}\right)$, which provides detailed insights into the characteristics and functioning of some of the world largest online platforms.

${ }^{4}$ This definition excludes online activities that do not involve digital marketplaces, such as e-commerce (direct online sale of own products to customers without third parties) and social media, but it includes third-party business-toconsumers and business-to-business activities.
} 


\section{8 | ECO/CPE/WP1(2020)6}

- Quality of institutions: Online platforms tend to develop faster in countries with a high degree of personal freedom, better control of corruption and an effective judiciary system. This corroborates the role played by institutional quality in spurring innovation and the deployment of new technologies (Dawson, 1998 ${ }_{[5]}$; Silve and Plekhanov, 2018[6]; Acemoglu and Robinson, 2010 $\left.{ }_{[7]}\right)$.

- Business environment: A lack of competition and barriers to entry in services markets (such as restrictive product market regulations and occupational licensing requirements) are associated with lower online platform diffusion and uptake.

- Digital policies: The ease with which online platforms can transfer data across jurisdictions is an important factor for online platforms' development, with cross-border data freedom being associated with larger platforms, especially international ones.

- Digital preparedness: Platform diffusion is greater in countries with better digital skills and quality of digital infrastructure, consistent with previous findings that technology adoption partly hinges on people and firms' capabilities - including access to connectivity and managerial and worker skills (Nicoletti, von Rueden and Andrews, 2020[8]).

7. However, in some policy areas the link with the diffusion of online platforms is complex, as it depends crucially on platforms' characteristics. For instance, disruptor platforms - which provide new types of products or services and are in direct competition with incumbent firms, (e.g. Uber) - tend to be less negatively affected by product market restrictions than aggregator platforms - which connect incumbent firms with consumers (e.g. Booking.com). Disruptor platforms might provide users with ways around restrictive product market regulations designed for traditional businesses.

8. The paper is organised as follows. Section 2 describes the data collection process. Section 3 provides main stylised facts about the diffusion platforms across countries and over time. Section 4 describes the analysis of online platform diffusion across different institutional settings and sets forward policy recommendations. Finally, Section 5 concludes the paper.

\section{Box 1. Selected OECD past and current work on online platforms}

In 2011, the OECD published a first report discussing a range of policy issues relating to the growing importance of internet intermediaries (OECD, 2011 $\left.{ }_{[14]}\right)$. The report acknowledged that internet intermediaries promote economic growth, innovation, and competition but also raise new challenges in different policy areas, including global free flow of information, security, and consumer protection. Since then, the OECD work on online platforms has covered many aspects of their operations and impacts on economies.

With a focus on overcoming measurement problems (discussed later more in detail), the OECD is working with other international organisations and national statistical agencies to better capture online platform activities in national accounts and improve cross-country comparability of data (OECD, 2018[8]; OECD, 2019[15]; OECD, 2019 [7]]).

OECD's Committees and Directorates have also investigated different aspects of online platforms and their operations. The Competition Committee has discussed in different meetings and publications key implications of online platforms' activities for competition policy (OECD, 2018 $\left.{ }_{[16]}\right)$, such as big data (OECD, 2016[17] $)$, algorithms (OECD, 2017 $\left.{ }_{[18]}\right)$ and consumer data rights (OECD, 2020[19]). 
Two reports on "Data-Driven Innovation" and "Enhancing Access to and Sharing of Data" (OECD, 2015[20]; OECD, 2019[21]) focus on how online platforms collect, analyse and use data across the economy. Peer to peer platforms in particular raise issues under traditional consumer protection frameworks (OECD, 2016[22]). The Committee for Consumer Policy undertook a survey to understand consumers' trust in peer platform markets (OECD, 2017[23]). The Digital Economic Policy Committee's (CDEP) Working Party on Data Governance and Privacy (WPDGP), part of the Directorate for Science, Technology and Innovation (STI), is currently reviewing the OECD's Privacy Guidelines, with the outcomes of the review expected by the end of 2020. The WPDGP is currently undertaking a project on "Data Portability", which is expected to run through 2020-21.

Another strand of OECD work focus on the new forms of work that online platforms entail. A paper prepared for the Cancún Ministerial (OECD, 2016[24]) highlights that online platforms pose challenges to existing institutions and regulatory frameworks, which may need to be reviewed but also that substantially better data are needed to evaluate the effects of online platforms. Another strand of work focuses on the new forms of work that online platforms entail and their impact on different dimensions of the labour market, such as quality of jobs, collective bargaining, social protection and productivity

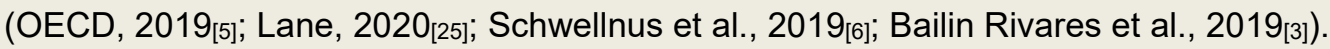

The Inclusive Framework on Base Erosion and Profit Shifting (BEPS) has been investigating the challenges online platforms (and the digital economy more broadly) pose for national and international taxation frameworks (OECD, 2015[26]; OECD, 2020 [27]). More specific work has focussed: on enhancing international cooperation among tax agencies by sharing of information on users of online platforms to ensure taxes are paid where they are due $\left(O E C D, 2018_{[28]}\right)$; on the role of platforms in collecting VAT on online trade (OECD, 2017 [29]); and on developing reporting model rules for online platforms (OECD, 2020[30]).

\section{Measuring online platform activity}

9. The term digital or online platforms has been used to describe a range of services available on the Internet including marketplaces, search engines, social media and app stores. This study follows the OECD report An Introduction to Online Platforms and their Role in the Digital Transformation (OECD, 2019), which defines digital platforms as those digital services that facilitate interactions between two or more distinct but interdependent sets of users (either firms or individuals) who interact through the service via the internet. For the purpose of this study, we further restrict our attention to platforms that facilitate the exchange of goods or services This definition excludes activities such as e-commerce, search engines, and social media but include third-party business-to-consumers and business-to-business activities as these services involve two separate sets of users. For example, Airbnb connects individuals wanting to rent out accommodation with those wishing to use it, and Booking.com connects mainly hotels with guests. Digital platforms create a two- or multi-sided market connecting users.

10. Internationally comparable data on the operations of platforms are scarce, hampering understanding of the structural and policy determinants of their diffusion and their impacts. At the country level, the measurement of online platforms' activity in official statistics needs improvements and national accounts currently do not explicitly capture the contribution of online platforms to macroeconomic activity. Currently business surveys can capture quite well the output, value added, employment of platforms themselves, but collecting country-by-country data directly from platforms would result in more comprehensive and internationally consistent recording. Moreover, due to privacy, commercial sensitiveness and security concerns, online platforms often refuse to provide independent researchers with the data necessary to evaluate the impact of their operations on the economy and society.

11. There are two main issues at stake relating to online-platform data: a) measuring platform activity and its socio-economic impact; b) using platform data to measure and understand broader socio-economic phenomena. The first one concerns the accounting and record of online platform activities, including their 
direct impact on consumer behaviour. The second issue concerns the access to big data collected by platforms, which may help to assess economic and social phenomena that online platforms affect only indirectly. For instance, mobility or electronic payment data can be used to measure changes - in a granular way, and in real time - of commuting and consumption patterns and their impact on the macroeconomy.

12. The OECD has been working, in collaboration with other international organisations and national statistical offices to overcome these problems (Box 2).

\section{Box 2. Efforts to better measure digital platforms and the digital economy}

The OECD is focussing on setting standards and procedures to collect better information on the operation of digital platforms across OECD countries. For instance, the OECD report Measuring Online Platforms and Cloud Computing in National Accounts (OECD, 2018) highlights the importance of collecting information on the numbers of platforms, customers, and suppliers, and their characteristics for the reliability of National Accounts while another report (OECD, 2019) has focussed on the challenges of measuring platform mediated workers.

Experiences of gathering these data directly from platform companies vary greatly as they are commercially sensitive and concerns about privacy and disclosure would need to be addressed. As a result, efforts to measure digital online platforms' activities remain rather piecemeal and focused on a specific subset of platforms.

Several countries have taken a proactive approach to covering platforms; for example, the United Kingdom Office for National Statistics identified (sharing-economy) platforms and included these in the Annual Business Survey and the E-commerce survey in 2016. A limitation of this approach is that it relies on platforms having a physical or legal presence in the country. However, the online nature of platforms' business models means that they are often active in countries without having any formal presence there and that they can route and process transactions in multiple ways (OECD, 2019).

Further progress in international coordinated efforts hinges on defining internationally accepted standards in the following areas: 1) collection of cross-country comparable data while addressing privacy and business related concerns; 2) explicit recognition of online platforms' activity in the system of national accounts; 3 ) development of protocols to promote the secure access of independent agencies, regulators and researchers to online platforms' data to monitor and facilitate in-depth studies on their activities.

The challenges concerning the access of big data collected by platforms are manifold. One crucial aspect regards the development of mutually agreed and trusted protocols enabling the access and use of platforms' data while meeting strict confidentiality requirements concerning personal data and commercially sensitive information. The Development Data Partnership, initiated by the World Bank, the International Monetary Fund and the Inter-American Development Bank, which the OECD recently joined, is the first forum where international organisations and platforms work together towards building the model for non-profit data sharing agreements. This still experimental initiative can be the springboard to expand and widen engagement with online platforms in a systematic and mutually agreed way.

13. This study attempts to shortcut some of these data challenges through a different approach, which relies on a mix of web-scraping techniques and use of commercially available databases on both digital platforms and their website traffic (OECD, 2018). We proceed in two steps. First, building on previous studies (OECD, 2019 ${ }_{[5]}$; Bailin Rivares et al., 2019 $\left.{ }_{[6]}\right)$, we create a list of the most popular platforms across all OECD and G20 countries (43 countries in total) and nine areas of activity using information coming from 
Crunchbase ${ }^{5}$ Crunchbase is a company providing information on private and public innovative companies. The information from Crunchbase was complemented with information from OECD country experts and specialised media. In this way, we were able to collect data not only on the largest, most international platforms, but also on smaller and local ones. The list of platforms was finalised in early 2020 and contains only the platforms active at that time. Trying to build a list of platforms no longer active and collect information on them would have involved substantial more efforts, with uncertain results in terms of coverage and comparability. As such, the dataset provides no information on exit while it provides information on the date platforms active in 2020 started operating in each country and sector we cover.

14. The activity areas covered include accommodation, marketplaces to consumers (MX2C), marketplaces business to business (B2B), ${ }^{6}$ mobile payments, personal services, professional services, restaurant booking, restaurant delivery, and transport. These areas were selected because of the growing importance of online platforms and their approximate matching with traditional services industries (such as food and accommodation or retail trade). Table 1 (panel A) presents the correspondence between industrial sectors and platform activity areas.

15. Second, to measure in a consistent way the diffusion and uptake of online platforms, the study uses website traffic data (i.e. the number of visits to online platforms' websites) sourced from Semrush (a leading private company that provides, among other services, market information on internet traffic to companies' websites). The assumption is that the number of visits to an online platform's website is correlated with the volume of activity of the platform, either because the platform is accessed directly through the website or because users are looking for information or tips when using the platform through mobile apps. ${ }^{7}$

16. Website traffic data are obviously just a proxy of the actual volume of activity of online platforms but they have the advantage of being consistent across platforms, countries, and years. Unlike data sourced from Google Trends and employed in previous studies, this measure is not standardised by the total number of Google searches in a country (thus it is not affected by the rising numbers of internet users and changes in the number of Google searches over time) and excludes searches for platforms that did not result in website visits and "false positives" (e.g., searches for "Bolt" reflect both users looking for the taxi platform and searches concerning the Olympic runner Usain Bolt).

17. The final dataset has information on around 1400 platforms, active in OECD and G20 countries (with the exception of China and Colombia) between 2013-2019. The number of countries covered in the database varies with the availability of traffic data, and changes over time, from 23 in 2013 to 43 after 2016 (Table 1, Panel B). Table A1 in Annex A lays out examples of platforms in each of the activity areas covered in this study.

\footnotetext{
${ }^{5}$ We do not include Colombia, as it was not an OECD member at the start of this study, nor China, as internet restrictions prevent from collecting data on website traffic.

${ }^{6}$ B2B platforms might differ significantly from B2C platforms, namely in terms of competition and size of users (IFO, $\left.2020_{[31]}\right)$, and as such the interpretation of data for the activity area "marketplace business to business" needs to be done with caution.

${ }^{7}$ We do not have access to the number of users with mobile apps or how much they use them. Accessing platforms through apps is likely to have surged in recent years, which imply our data may underestimate the increase in the use of platforms. This also means that the suitability of website traffic as proxy of platform use may vary across activity areaa. In some areas (e.g.: accommodation) users may be more likely to access online platform services through the website than in others (e.g.: taxi).
} 


\section{Table 1. Sectors and countries covered in the sample}

Panel A: Platform areas and corresponding traditional sectors

\begin{tabular}{lll}
\hline Platform area & Sectors affected \\
\hline Marketplace X2C & 47 & Retail trade \\
Marketplace B2B & 46 & Wholesale trade \\
Restaurants (booking \& delivery) & 56 & Food and beverage service activities \\
Transport & 49 & Land transport and transport pipelines \\
Accommodation & 55 & Accommodation \\
\hline Professional services & 62 & Computer programming, consultancy and related activities \\
& 69 & Legal and accounting activities \\
& 71 & Architectural and engineering activities; technical testing and analysis \\
& 73 & Advertising and market research \\
\hline Personal services & 74 & Other professional, scientific and technical activities \\
& 43 & Specialised construction activities \\
\hline & 81 & Services to buildings and landscape activities \\
Mobile payments & 95 & Repair of computers and personal and household goods \\
\hline Panel B: List of & 96 & Other personal service activities \\
\hline
\end{tabular}

Panel B: List of countries and years for which data is available

\begin{tabular}{ll}
\hline \multicolumn{1}{c}{ Period } & \multicolumn{1}{c}{ List of countries } \\
\hline 2013-2014 & $\begin{array}{l}\text { Argentina, Australia, Belgium, Brazil, Canada, Switzerland, Germany, Denmark, Spain, Finland, France, Great } \\
\text { Britain, Ireland, Israel, Italy, Mexico, Netherlands, Norway, Poland, Russia, Sweden, Turkey, United States (23 } \\
\text { countries) }\end{array}$ \\
& As 2013- 2015 plus Hungary, India, Japan (26 countries) \\
2015 & As 2015 plus Austria, Chile, Czech Republic, Estonia, Greece, Iceland, Indonesia, Korea, Lithuania, \\
$2016-2019$ & Luxembourg, Latvia, New Zealand, Portugal, Saudi Arabia, Slovakia, Slovenia, South Africa (43 countries) \\
\hline
\end{tabular}

Source: OECD.

18. Based on the inspection of each online platform's website, we further classify online platforms along six dimensions. These are consistent with previous OECD work (OECD, 2019[5]; Bailin Rivares et al., $2019_{[6]}$ ) and potentially relevant for policy (Figure 1): ${ }^{8}$

- Aggregator or disruptor (score one to five). Aggregator platforms are those that connect existing service providers with consumers, for example by facilitating delivery of services or enabling trust through review systems (e.g. Booking.com); disruptor platforms are those that connect consumers with new service providers, whose activity is enabled by the platform, in direct competition with existing providers (e.g. Airbnb, Uber). These two types of platforms share many characteristics (e.g., the use of review and rating and review systems) but their effects on traditional businesses might differ. While the effect of disruptor platforms on incumbents is mainly attributable to increased competition (caused by the entry of new providers), the effect of aggregator platforms is more complex, consisting of a mixture of competition and technology shocks.

- Labour or capital intensive (score one to five). This definition is based on (OECD, 2016 $[7]$ ) and measures the perceived intensity of labour and capital used for the provision of products/services (e.g. Apple Pay and Airbnb are more capital intensive than Uber or Taskrabbit). Labour market policies, in addition to others such as property taxes, are likely to affect differently labour and capital intensive.

\footnotetext{
${ }^{8}$ A mapping of characteristics to scores and examples of platform classification are available in Figure A1 and Table A2 in Annex 1.
} 
- Degree of review intensity (score one to five). This is based on the review and rating system of the platform. If both parties (seller and buyer) are evaluated with ratings and reviews the platform is considered to have the maximum review intensity (e.g. Airbnb). The degree of review intensity declines as parties can rate the counterpart through a point system (ratings) and when just one party can do this. The minimum review intensity corresponds to the situation when neither reviews nor ratings are allowed for the parties involved (e.g. Apple Pay). Studies have shown that the quality of platform-mediated services, as measured by review systems, plays an important role in user uptake (Farronato et al., 2020[8]).

- Digital vs physical delivery (score one, three or five). This measure, based on (OECD, 2016[7] ), reflects how much the service delivery depends on physical proximity, with delivery being sometimes completely dependent on proximity (e.g. Amazon, Airbnb, Uber) and others being fully digital (e.g. Mechanical Turk, Paypal). Platforms mediating digitally-delivered services will usually have different business models and be subject to different regulations. For example, requirements for commercial presence in a country may be more binding for platforms with only digital services than for those with physical delivery of services.

- Degree of internationalisation (number of countries). This measures the extent to which platforms are active in different countries. Platforms operating in more countries can benefit from economies of scale and sharing of information, if data can be easily transferred across across borders; domestic platforms face the challenge of reaching critical mass in a single market.

- Sector diversification (score one to three). This measures the number of activity areas in which a platform operates. Diversified platforms can take advantage of data sharing, especially when this is not possible between platforms, to more easily benefit from economies of scale or scope.

19. Figure 1 provides additional examples on how policies can have a different impact on platform use depending on platform characteristics. For instance, a decrease in restrictions on cross border data flows is more likely to impact positively the use of international platforms than local ones as they can benefit from transferring data across countries. Administrative burdens or legal costs that affect mostly start-ups might spur the use of disruptor platforms, which can provide a way to circumvent these costs, while not affecting the use of aggregators.

\section{Figure 1. Potential links between platform categories and selected policies}

\begin{tabular}{|c|c|c|}
\hline Dimensions of tags & Policy example & Possible impact \\
\hline $\begin{array}{l}\text { Capital/Labor intensity } \\
\text { 5-1 }\end{array}$ & $\begin{array}{l}\text { Employment } \\
\text { protection }\end{array}$ & $\begin{array}{l}\text { Higher barriers to entry in traditional jobs affect the diffusion of } \\
\text { labor intensive platforms }\end{array}$ \\
\hline Digital/Physical delivery & Infrastructure & Access to high speed internet/quality of the internet should affect \\
\hline $5-1$ & availability & $\begin{array}{l}\text { platforms with digital delivery more than those with physical } \\
\text { delivery }\end{array}$ \\
\hline $\begin{array}{l}\text { Aggregator/Disruptor } \\
5-1\end{array}$ & $\begin{array}{l}\text { Admin. Burden on } \\
\text { Start-ups (OMR) }\end{array}$ & Burdens on start-ups might increase the use of disruptors \\
\hline $\begin{array}{l}\text { Review heavy/light } \\
5-1\end{array}$ & $\begin{array}{l}\text { Occupational licensing } \\
\text { restrictions }\end{array}$ & $\begin{array}{l}\text { Level of OL as a proxy for preference for quality: impact on review } \\
\text { heavy platforms }\end{array}$ \\
\hline $\begin{array}{c}\text { Global/Local } \\
43-1\end{array}$ & $\begin{array}{l}\text { Cross border data flow } \\
\text { restrictions }\end{array}$ & $\begin{array}{l}\text { Cross border data flows are likely more important for international } \\
\text { firms }\end{array}$ \\
\hline $\begin{array}{l}\text { Diversified/Specialised } \\
\text { 3-1 }\end{array}$ & Data portability rules & $\begin{array}{l}\text { Data portability rules reduce switching costs for consumers, thus } \\
\text { reducing the disproportionate network effects of platforms } \\
\text { operating in multiple markets. }\end{array}$ \\
\hline
\end{tabular}




\section{Online platform diffusion over the past decade: stylised facts}

\subsection{Online platforms' diffusion has been fast and ubiquitous but differs across activity areas}

20. Online platforms have developed rapidly in the recent past. The total number of unique active online platforms in the dataset used in this study increased by more than $50 \%$ from 2013 to 2019 (to around 1400). ${ }^{9}$ The average number of active platforms per country went up from 200 to more than 600 over the same period (Figure 2, Panel A) while the total digital-platform traffic per capita rose fourfold (Figure 2, Panel B). As highlighted in the previous section, the rising number of active platforms could also be due to survival bias as platforms that ceased operations before 2020 are not recorded. For the 23 countries available since 2013 , online platform traffic experienced a three-fold increase. This is comparable to the growth in global fixed internet traffic over the same period. ${ }^{10}$

21. Online platform traffic is rising steeply in all areas of activity. Starting from 2016 (the first year for which data are available for all 43 countries), marketplace business-to-business, personal services, professional services and restaurant delivery were the areas with the largest increases in traffic, though from a very low base (Table 2). However, online platforms operating in the marketplace to consumers area account by far for the largest share of total online platform traffic. The share of traffic of accommodation, the second largest activity area, is below $10 \%$ of that of marketplaces to consumers. (Table 3 )

\section{Figure 2. Online platforms have developed rapidly over the past decade}

Panel A: Total number of platforms is rising

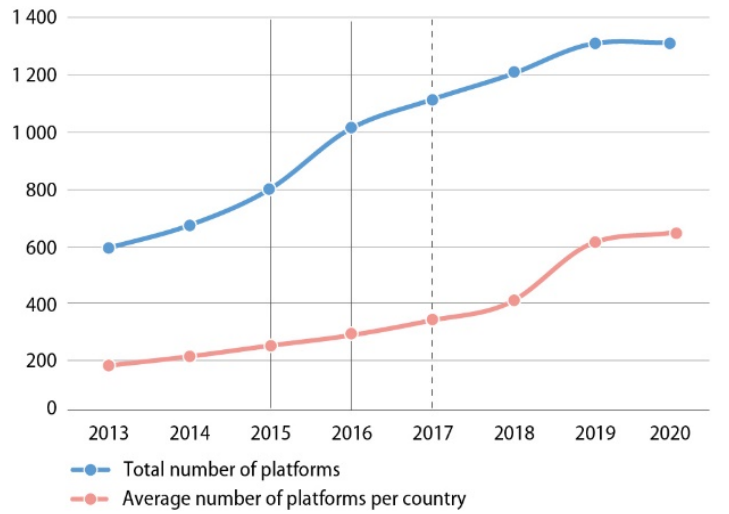

Panel B: Platform website traffic per capita is rising

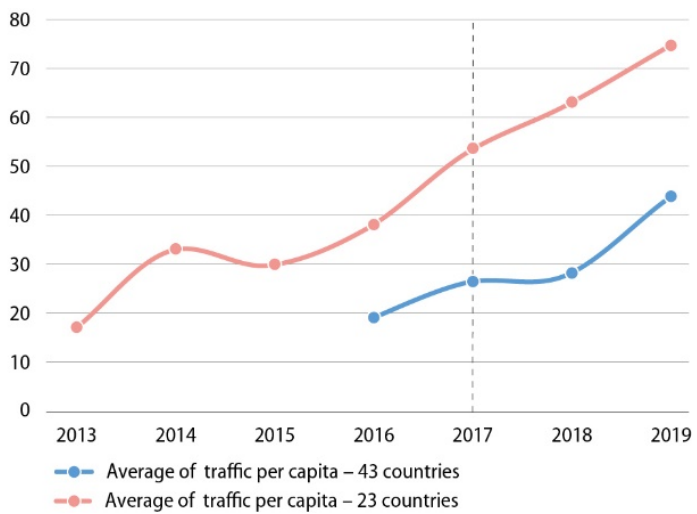

Note: Solid vertical lines indicate the years where the number of countries increases; dotted vertical line indicates the structural break in the way Semrush collects data (December 2016). In panel B, platforms' website traffic per capita is measured as the arithmetic average across countries of the number of visits to all platforms' websites in a country over the population of the country. The 23 countries are those for which information is available for the entire period: Argentina, Australia, Belgium, Brazil, Canada, Switzerland, Germany, Denmark, Spain, Finland, France, Great Britain, Ireland, Israel, Italy, Mexico, Netherlands, Norway, Poland, Russia, Sweden, Turkey, United States. The 43 countries are the entire sample; data is presented only for the years where data is available for all (2016-2019).

\footnotetext{
${ }^{9}$ Many of these platforms (such as Amazon, Airbnb, Uber...) are present across many countries. The total number of unique platforms is lower than the total sum of active platforms in each country as platforms may be active in many countries (through different websites, such Amazon.uk and Amazon.fr, or just one website, uber.com).

10 See https://en.wikipedia.org/wiki/Internet traffic and the Cisco's Annual Internet Reports.
} 
Table 2. Dynamics of online platforms traffic by sector

Traffic to online platforms website; index $2016=100$

\begin{tabular}{llcc}
\hline Year & 2017 & 2018 & 2019 \\
\hline Accommodation & 160.1 & 222.5 & 267.7 \\
Marketplace B2B & 436.4 & 879.8 & 1227.0 \\
Marketplace X2C & 128.6 & 158.3 & 184.6 \\
Mobile Payments & 124.8 & 194.9 & 239.9 \\
Personal Services & 139.7 & 170.5 & 206.6 \\
Professional Services & 157.1 & 184.6 & 235.9 \\
Restaurant Booking & 137.7 & 268.8 & 274.3 \\
Restaurant Delivery & 158.6 & 361.7 & 510.4 \\
Transport/Taxi & 137.0 & 242.9 & 267.5 \\
\hline
\end{tabular}

Source: OECD computations with data from Semrush and Crunchbase.

22. The huge size of digital marketplaces serving retail customers compared with those operating in other areas can be ascribed to two main factors: international trade and changes in the structure of online retail markets. First, online platforms in the marketplace to consumers area can generate large network effects at a global scale, creating global clusters (Zhu and lansiti, 2019[9] - as they deal mostly with tradeable goods. For instance, in 2019 more than 40\% of the sellers operating in Amazon's marketplaces were based in China (from less than $30 \%$ on 2017) despite Amazon having shut down its operations therein. Second, over time some large online retailers have evolved from being simple sellers to online marketplaces by allowing an increasing number of independent third-party sellers to trade with consumers on their website. Amazon is a prime example of this transformation. As a share of total revenues, Amazon's online sales went down from $72 \%$ in 2015 to $50 \%$ in 2019 whereas marketplace revenues (i.e. fees that third party sellers pay to Amazon) rose from $15 \%$ to $20 \%$ over the same period (Marketplace Pulse, $\left.2020_{[10]}\right)$. On the other hand, some other very large digital marketplaces that started later than Amazon, such as Alibaba and Rakuten, began operating directly as online platforms, having no own inventory and relying instead on external goods and services providers.

23. The number and average size of online platforms varies greatly across areas of activity both globally and across countries (Figure 3). Marketplace to consumers and accommodation are the areas of activity with the largest total number of platforms. The areas of activity with a higher number of platforms are also those with a larger total traffic (Table 3). The same activity ranking holds across countries, though with significant variation in absolute numbers by area of activity. The United States is the country with the largest number of online platforms in all areas, except for marketplace to consumers. 
Figure 3. The number of platforms varies across sectors

A: Total number of unique platforms by sector

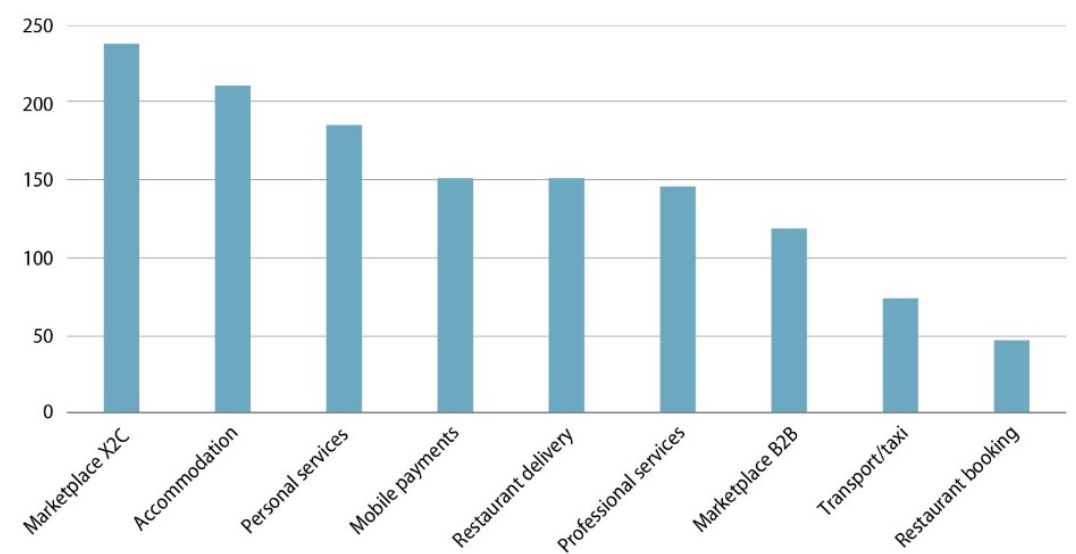

B: The number of platforms by sector varies across countries

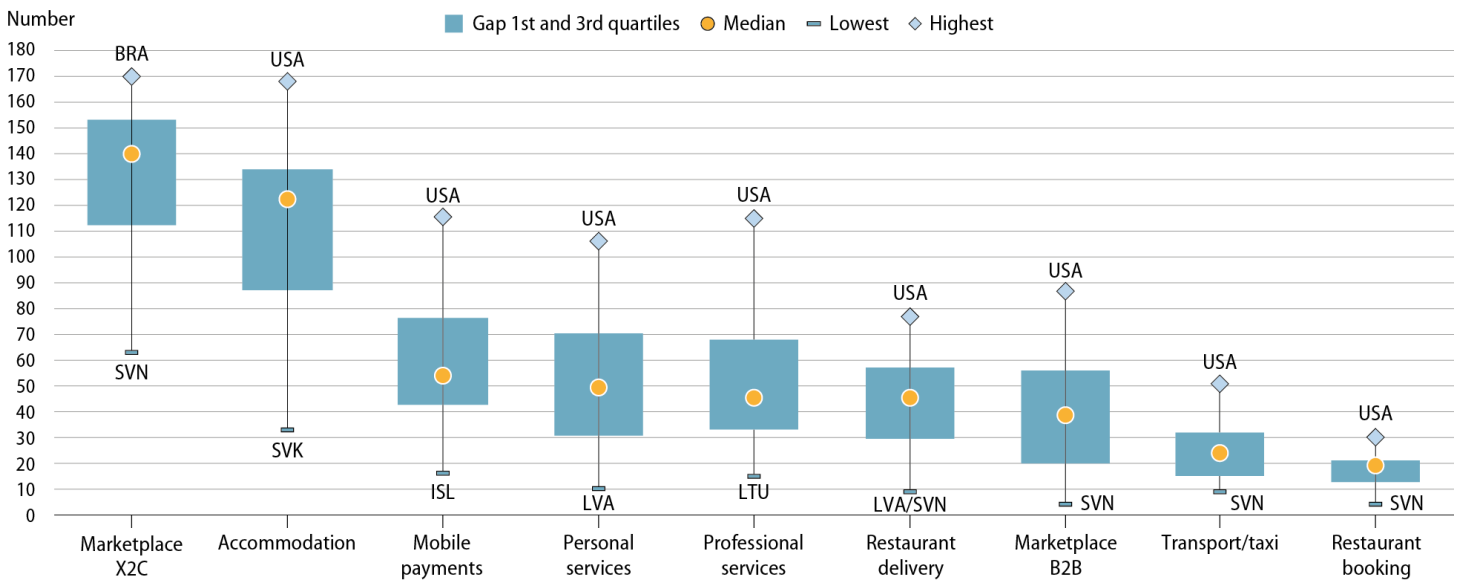

Note: In panel B for each activity area, the low horizontal marks show the number of active platforms in the country with the lowest number of platforms; the diamonds the number of platforms in the country with the highest number of platforms; the circle represents the median number of platforms and the blue box the interquartile range.

Source: OECD calculations based on Semrush and Crunchbase data.

Table 3. Size of online platform traffic by sector

Total online platforms' traffic by sector compared to largest sector (Marketplace to Consumers indexed to 100)

\begin{tabular}{lccccccc}
\hline \multicolumn{1}{c}{ Year } & 2013 & 2014 & 2015 & 2016 & 2017 & 2018 & 2019 \\
\hline Accommodation & 3.8 & 4.3 & 4.8 & 4.3 & 5.4 & 6.1 & 6.3 \\
Marketplace B2B & 0.3 & 0.3 & 0.3 & 0.3 & 1.1 & 1.7 & 2.1 \\
Mobile Payments & 0.6 & 0.8 & 2.1 & 2.7 & 2.6 & 3.3 & 3.5 \\
Personal Services & 1.4 & 1.8 & 1.9 & 1.7 & 1.9 & 1.9 & 2.0 \\
Professional Services & 0.1 & 0.2 & 0.1 & 0.1 & 0.2 & 0.1 & 0.2 \\
Restaurant Booking & 0.1 & 0.2 & 1.0 & 1.1 & 1.2 & 1.8 & 1.6 \\
Restaurant Delivery & 0.2 & 0.3 & 0.5 & 0.5 & 0.6 & 1.1 & 1.4 \\
Transport/Taxi & 0.3 & 0.4 & 0.5 & 0.6 & 0.6 & 0.8 & 0.8 \\
\hline
\end{tabular}

Source: OECD calculations based on data from Semrush and Crunchbase. 


\subsection{Network and income effects drive online platforms' penetration}

24. Network effects are a potentially important feature of multi-sided markets (see Box 3). Network along with income effects seem to drive online platforms' penetration across countries. First, several populous and high-income countries - such as the Germany, Japan, and the United States- have the highest total online platforms' traffic per capita and the smallest number of platforms per capita (Figure 4). However, income and population explain only part of the cross-country variation in online platform development. The residual variation is likely to be attributable to other country characteristics and policies (Section 3).

\section{Box 3. Multi-sided online platforms and network effects}

Multisided online platforms are defined as those online platforms attracting two or more groups of users to facilitate the exchange of goods and services among them. The pioneering studies of multisided platforms (Caillaud and Jullien, $\left(2001_{[12]}\right) \&\left(2003_{[13]}\right)$, (Rochet and Tirole, 2003[17]; Parker and Van Alstyne, $2005_{[18]}$; Armstrong, 2006 $\left.\left.6_{[19]}\right)\right)$ highlighted network effects as the identifying feature of multisided platforms.

Economists and practitioners have long recognised the effects of network externalities, starting with the development of the old physical networks such as the railroads and the electricity systems. The extent to which digital networks have proliferated in the economy is a recent phenomenon but the network effects they engender are similar to those of older network companies. Network externalities exist when the utility a user derives from a technology/good or service is increasing as the number of other users of the same (or a compatible) technology/good or service rises (Katz and Shapiro, 1985). For example, the more people there are in a telephone network the more users can be reached on the network, thereby increasing its usability. Broadcast industry services, credit card networks, and computer hardware and software are other examples.

Positive network externalities mean new users tend to pick platforms that are already larger, and thus are a form of increasing returns to scale. This can give rise to a winner-take-all dynamic in which a network/platform comes to dominate the industry. In the past, winner-take-all dynamics have called for government interventions and break up of dominant networks. Today, the focus has shifted towards enhancing interconnection, compatibility, and data portability.

Network effects are not necessarily positive, and negative externalities can arise in the context of platforms, namely due to congestion and competition for buyers (Belleflamme and Peitz, 2019[30]). This factor, particularly relevant for B2B platforms (IFO, 2020[31]), might help justify why we do not necessarily observe a single large platform in the market. 
Figure 4. Larger and richer countries tend to have more traffic but less platforms per capita Platforms' website traffic per capita and number of platforms capita, 2019

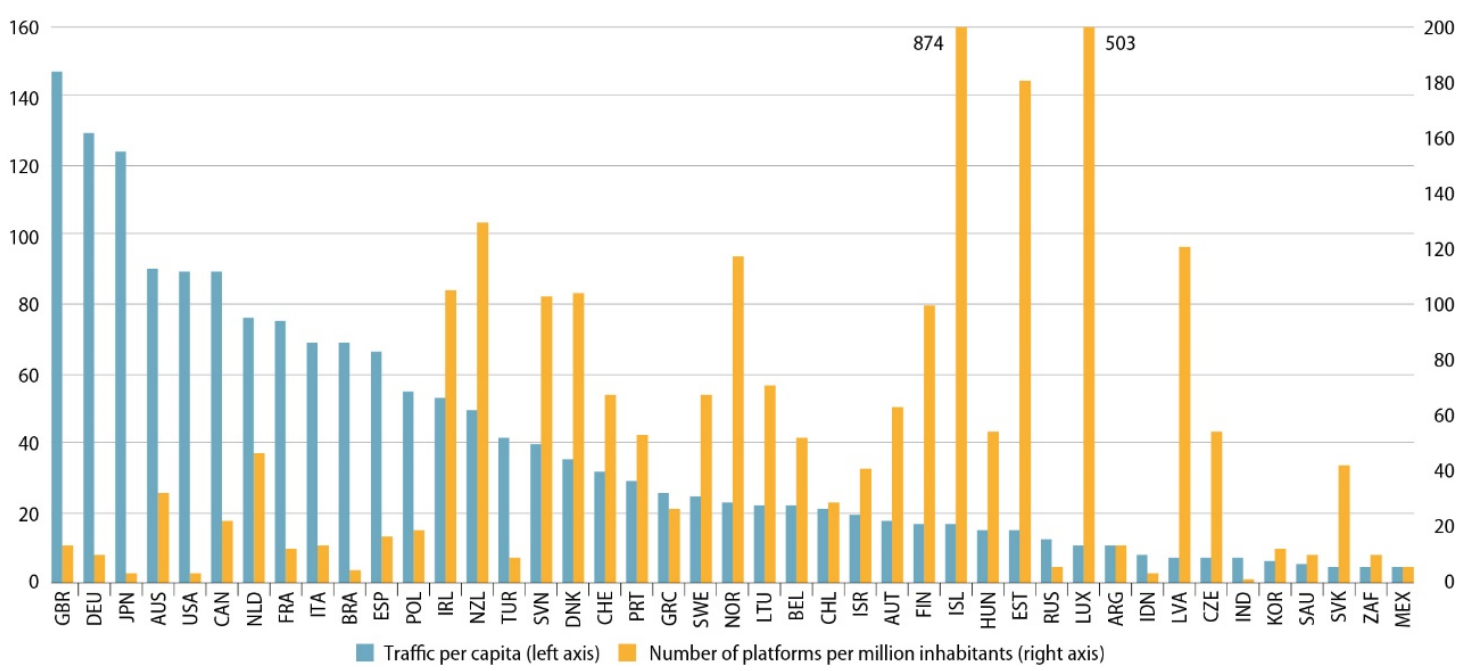

Note: Right axis is capped at 200 for clarity as Iceland and Luxembourg's platforms per capita are outliers. Platforms' traffic per capita is measured by the number of visits to platforms' websites person. Number of platforms per capita is computed as number of platforms per of per capita.

Source: OECD calculations based on data from Semrush and Crunchbase.

25. Two related stylised facts point to the existence of network effects: 1) higher total traffic is associated with larger platforms (i.e. higher traffic per platform) (Figure 5, panel A); 2) the average size of platforms (i.e. traffic per platform) is negatively associated with the number of platforms per capita (Figure 5, panel B). ${ }^{11}$ In other words, the larger digital-platform traffic per capita of more populous and wealthy countries is attributable to platforms being on average larger (generating more traffic) and not to a higher number of platforms per capita.

${ }^{11}$ In addition, economies of scale and scope are also likely to be present. We focus on these in the following sections. 
Figure 5. Platform traffic per capita is associated with larger platforms, suggesting the presence of network effects

Panel A. Traffic per capita and size of platforms, 2017-19

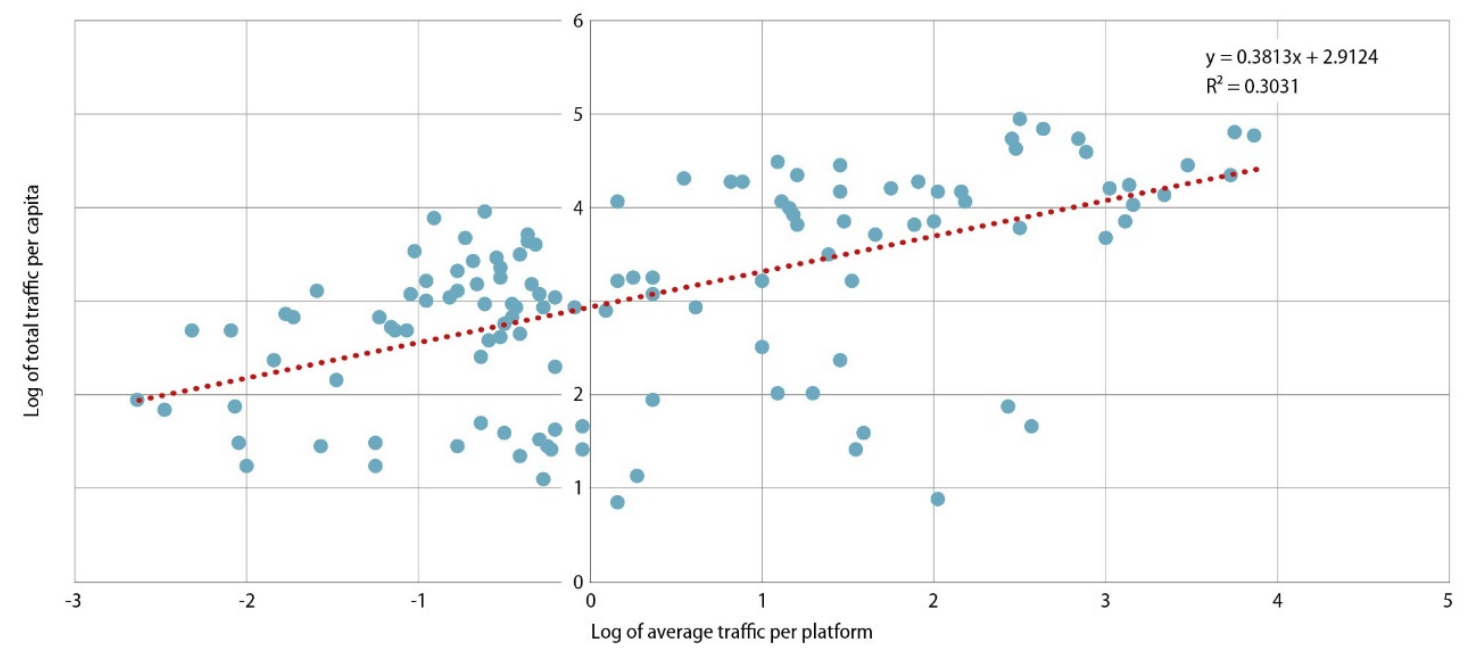

Panel B. Number of platforms and size of platforms, 2017-2019

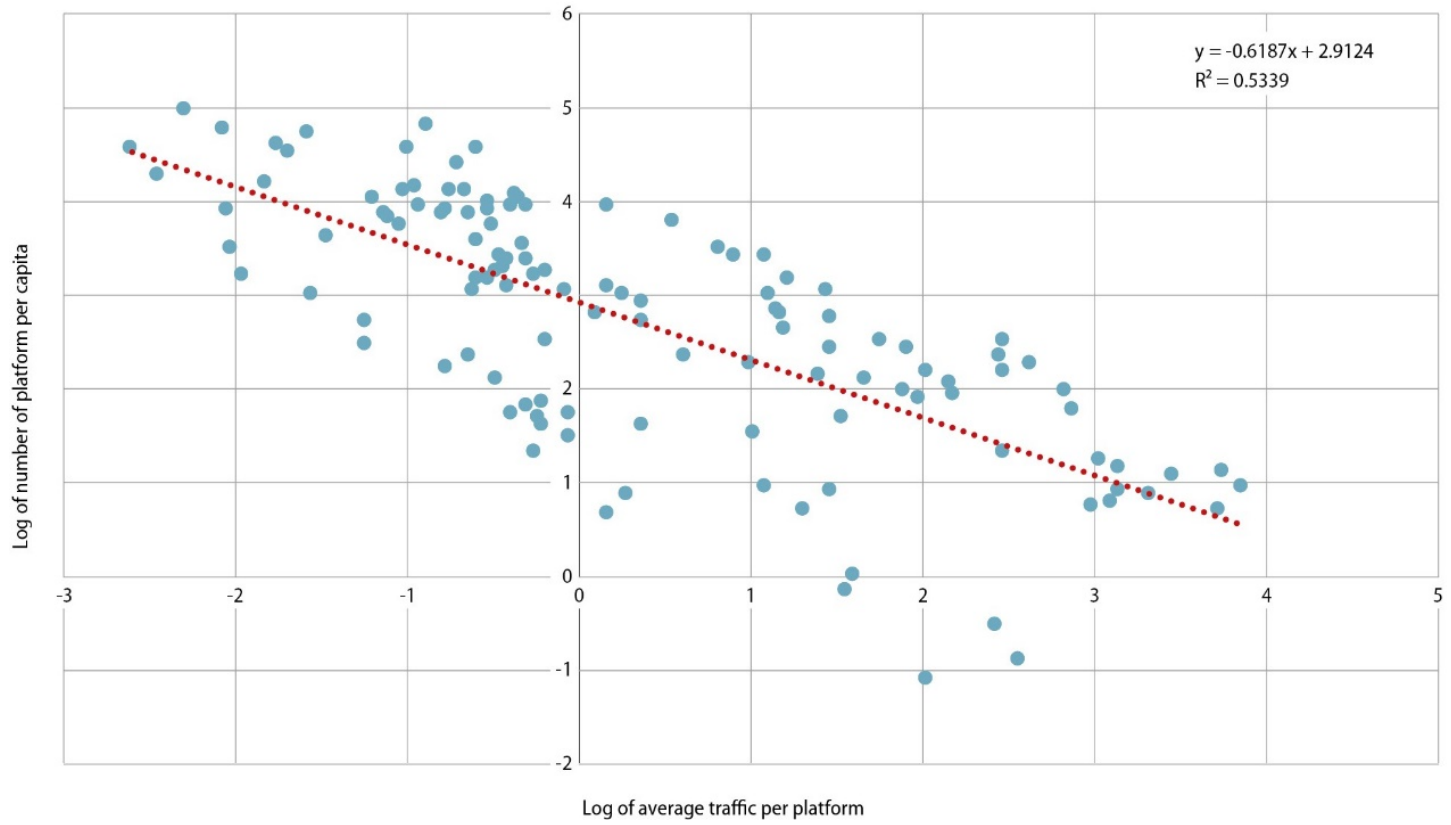

Note: For the sake of clarity the graphs exclude Iceland and Luxemburg as they are outliers; their inclusion do not change the interpretation of the charts.

Source: OECD calculations based on data from Semrush and Crunchbase.

\subsection{Online platforms are increasingly global but specialized in few activities}

\subsubsection{Online platforms typically operate on a global scale}

26. Most of the online platforms data have operations in a large number of countries. In 2019, nearly $50 \%$ of platforms operated in at least 35 countries (Figure 6, panel A); about $20 \%$ of platforms operated in all 43 countries covered by our data, generating over $80 \%$ of total traffic. Only a tiny share (just over $1 \%$ ) 
of platforms had operations in just one country, though they accounted for $2.5 \%$ of total digital-platform traffic. The average number of countries in which online platforms operate has been increasing over time, suggesting that platforms are becoming more international over time.

27. Platforms operating in all countries are on average very large, nearly four times larger than the average platform. However, platforms operating in few countries are also large. For instance, platforms operating in just one country are three times larger than the average platform while those operating in less than five countries are one and half times larger. Overall, there is a U-shaped relationship between the size of platforms (measured by traffic) and the number of countries in which platforms operate. This might again indicate the importance of network effects as platforms operating in just one or few countries still need to reach a large number of users to be viable online marketplaces.

28. Across areas of activity, accommodation and marketplace to consumers are those with the highest share of global platforms (i.e. those operating in all countries) whereas restaurant delivery, business-tobusiness and personal services are those with the lowest (Figure 6, panel B). This could be partially explained by the size of online marketplaces. Marketplace to consumers and accommodation are the largest areas of activity, having been developing for several years, while activity in restaurant delivery and personal services is smaller and has developed more recently. Global platforms tend to target larger markets, and in areas where network effects are important the first-mover advantage implies that they can have lasting market dominance (Lehdonvirta et al., 2020[14]).

29. The large number of geographic markets in which most online platforms operate is consistent with the low marginal costs associated with the "scale-without-mass" hypothesis allowed by digitalisation (Brynjolfsson et al., 2007 ${ }_{[15]}$ ). The business model of online platforms, built on new technologies and network effects, allows for the replication of operations across countries at little or no additional cost, making it easy to start and scale up operations in new countries. For this reason, the business model of online platforms does not appear to follow the traditional process of export market entry and FDI highlighted by the international trade literature literature (Bernard and Jensen, 1995[23]; Helpman, Melitz and Yeaple, $2004_{[24]}$, whereby only the most productive and bigger firms self-select into international markets due to a mix of sunk costs of entry and heterogeneous productivity levels. With low or zero marginal costs and low sunk costs of entry allowed by the scale-without-mass technology, many online platforms operate in different countries without even having a physical presence there, making entry in these new markets easier than in more traditional sectors. This case is common in the European Union as often large international platforms set up a European base in one country (often the United Kingdom or Luxembourg) from which to operate throughout the region (OECD, 2018[3]). 
Figure 6. A minority of global platform generate most of the traffic

A. Degree of internationalisation, year 2019

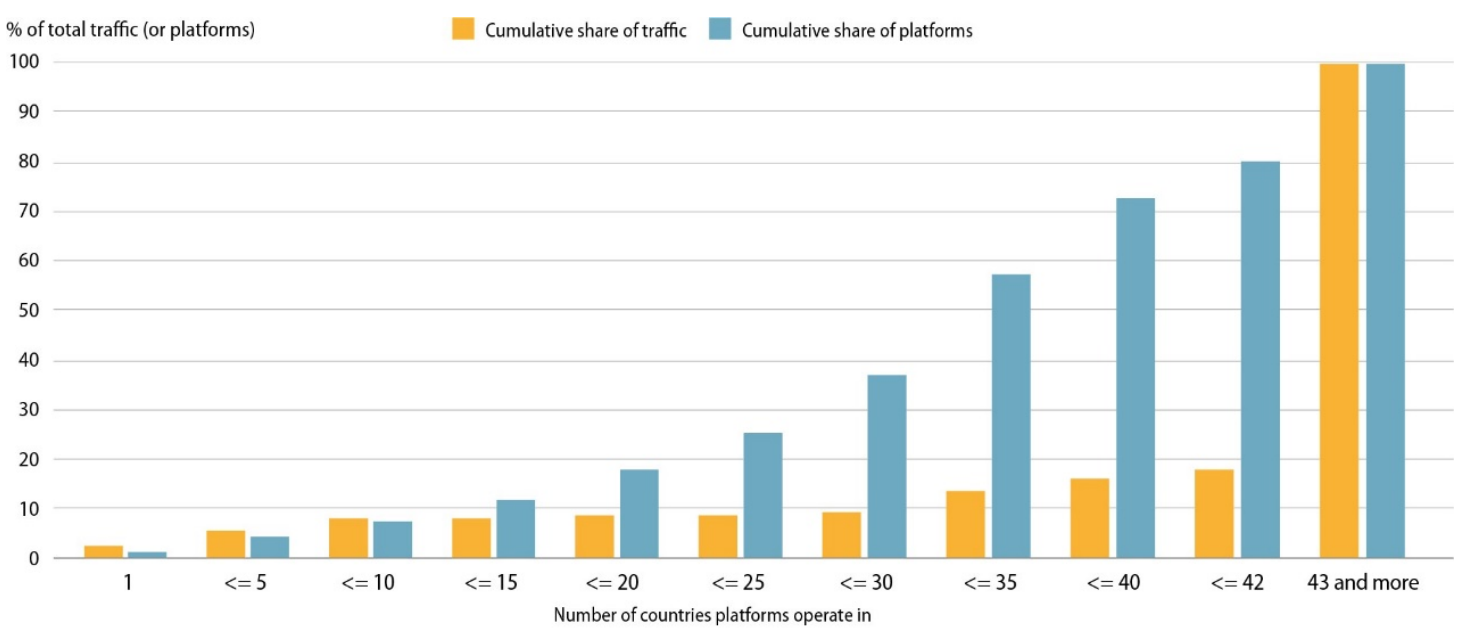

B. Share of traffic and share of platforms that operate in all 43 countries in the dataset, year 2019

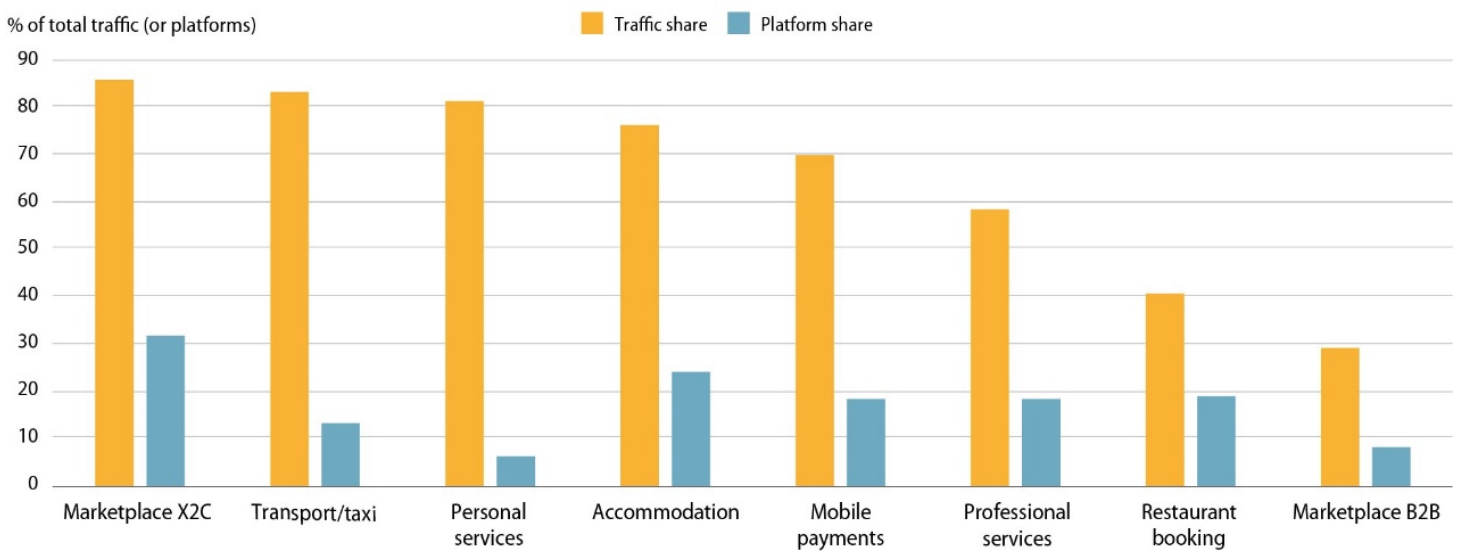

Source: OECD calculations with data from Semrush and Crunchbase.

\subsubsection{Most online platforms operate in just one area of activity}

30. The degree of diversification of online platforms across activity areas is limited. Most online platforms operate in just one of the areas of activity under analysis and the maximum number of activity areas, as defined in our study, in which platforms operate is three (Figure 7). The low degree of diversification of most online platforms suggests that they enjoy limited economies of scope, at least across the activity areas used in this study. ${ }^{12}$ This differs from traditional sectors where multiproduct and multiservice companies are the norm, especially among large businesses (Panzar and Willing, 1981 [25]; Treece, 1982[26]).

31. Diversified platforms are however larger on average than specialised ones. That only few online platforms are active in multiple activity areas and that these tend to be larger than specialised ones suggest the existence of high sunk costs of diversification and of starting operations in new activity areas. It is unclear to what extent these sunk costs are related to technology or to regulatory obstacles to diversification (e.g. sharing data across activities). In any case, only few online platforms are able to afford

${ }^{12}$ Defining activity areas in a more narrow way will likely result in larger economies of scope. 
such costs and those that do are able to further expand their operations. This mechanism is akin to that highlighted in the international trade literature to explain the presence of multiproduct firms (Bernard, Redding and Schott, $\left.2011_{[27]}\right)$.

\section{Figure 7. Most online platforms operate in just one area of activity}

Share of traffic and platforms by number of sectors operated in, year 2019

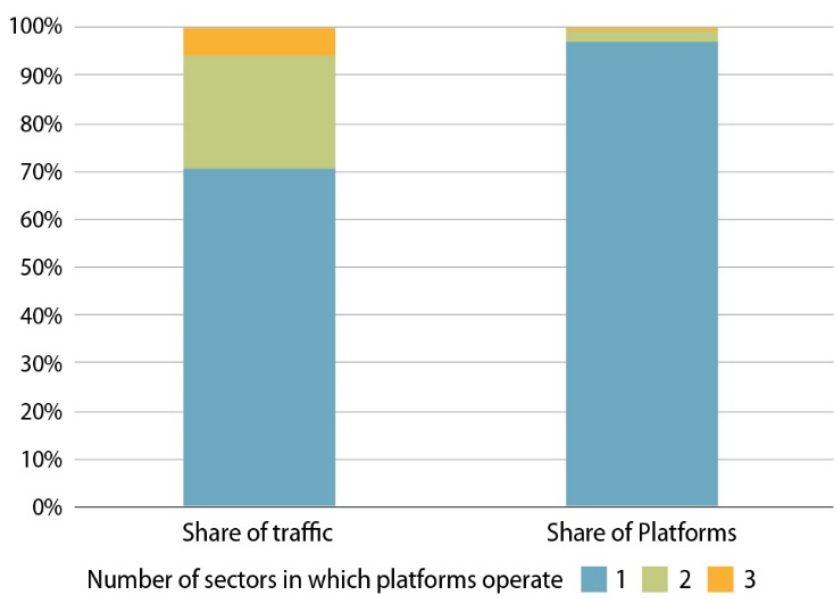

Source: OECD calculations with data from Semrush and Crunchbase

\subsection{Are platforms getting too big?}

\subsubsection{Concentration varies by sector but has declined over time}

32. The rapid development of online platforms and the emergence of very large ones have raised concerns about high levels of market concentration and the risks of abuse of market power that this may entail. Measuring concentration of online platform markets is difficult, as comparable data on platform activity and revenues are lacking. Here, the proxy for platform activity (platform website visits, i.e. traffic) is used to measure traffic concentration. This is related to market concentration only under the assumption that platform activity and revenues are proportional to traffic. ${ }^{13}$

33. The concentration of online platforms' traffic is estimated for each area of activity. There are arguments against relying on concentration measures at the industry level, for example based on NAICS or SIC categories. First, industries or areas of activity are not necessarily markets as industries reflect the relatedness of products, services and production processes comprising them. Second, concentration measures are only one indicator among many to be taken into consideration when assessing market power and the degree of competition. Other useful indicators, complementary to concentration indexes, include output, prices, mark-ups, profits, degree of churn, entry and exit (OECD, 2018[28]). Unfortunately, these indicators are difficult to get by and not available for the list of online platforms used in this study. The concentration measures discussed below provide then only a partial view of the degree of competition and its evolution of online-platform markets.

34. The global concentration of online platforms' traffic (computed by summing traffic across all countries) varies greatly across areas of activity (Figure 8). The traffic share of the largest four platforms (CR4 index) is especially high in transport and restaurant booking, where the largest four online platforms

13 This proportionality will likely vary across business models (e.g. advertising versus subscription). 
account for about $90 \%$ of total traffic. Interestingly, global traffic concentration indices have been decreasing over time in several areas of platform activity. ${ }^{14}$

35. These global traffic concentration measures are likely to be driven by the platforms operating in the most populous and richest countries as they account for the largest amount of traffic and have the largest platforms. Figure 9 (panel A) shows the CR4 index for each area of activity and country in 2019. The sectoral CR4 indices also vary greatly across countries possibly on account of differences in policies and the stages of development of digital marketplaces. In the areas of restaurant booking, restaurant delivery and transport, traffic is highly concentrated in most countries while the median CR4 index is lowest for professional services and marketplace to consumers, though the level of dispersion is high.

36. These CR4 indices computed at the activity area and country level have also been decreasing over time. Between 2016 and 2019, the country median of this index decreased in all areas considered (Figure 9, panel B), with professional services recording the largest reduction, followed by mobile payments and personal services. This declining trend was not observed in China, however, where a movement towards consolidation of existing platforms appears to have increased concentration levels over the past decade (Box 4).

Figure 8. Online platform global traffic concentration varies across areas of activity and has decreased over time

Share of traffic of the largest four platforms in each activity area, 2017-2019

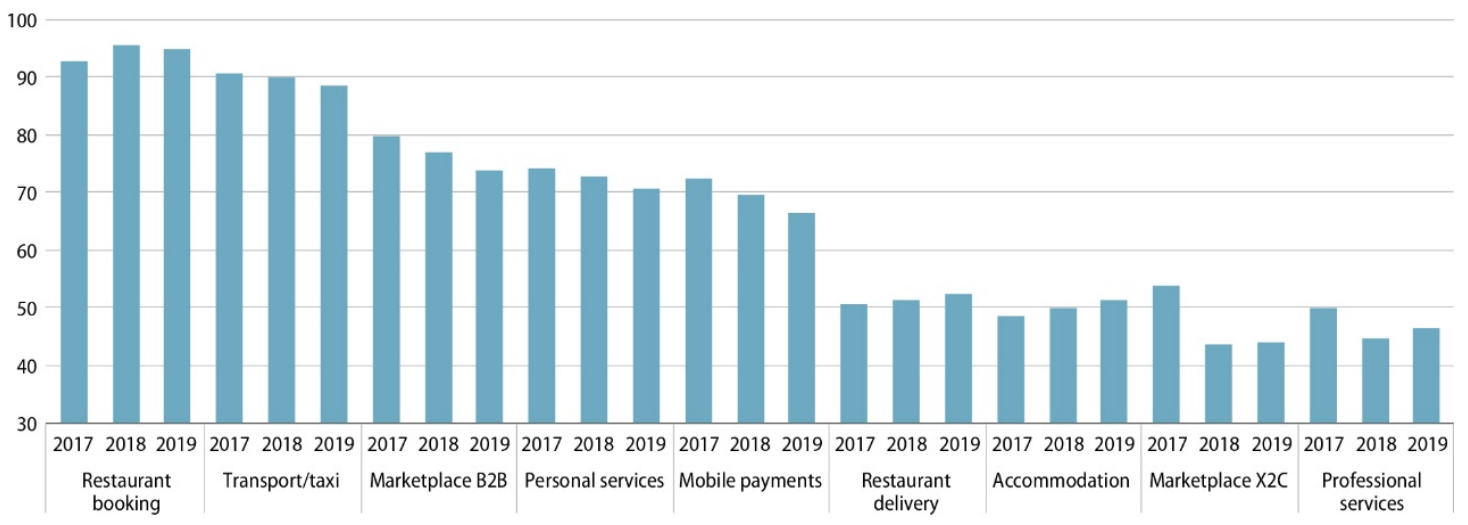

Note: Areas of activity are organized according to the 2017-2019 average of the share of traffic of the largest 4 platforms (CR4). Source: OECD calculations with data from Semrush and Crunchbase.

\footnotetext{
14 The report estimates traffic concentration only for the years 2017-2019, given that the change in methodology in 2017 would result in artificial changes in the concentration measure.
} 


\section{4 | ECO/CPE/WP1(2020)6}

Figure 9. Online platform traffic concentration by sector varies across countries and has also been decreasing over time

A. Share of traffic of four largest platforms by sector and country, 2019

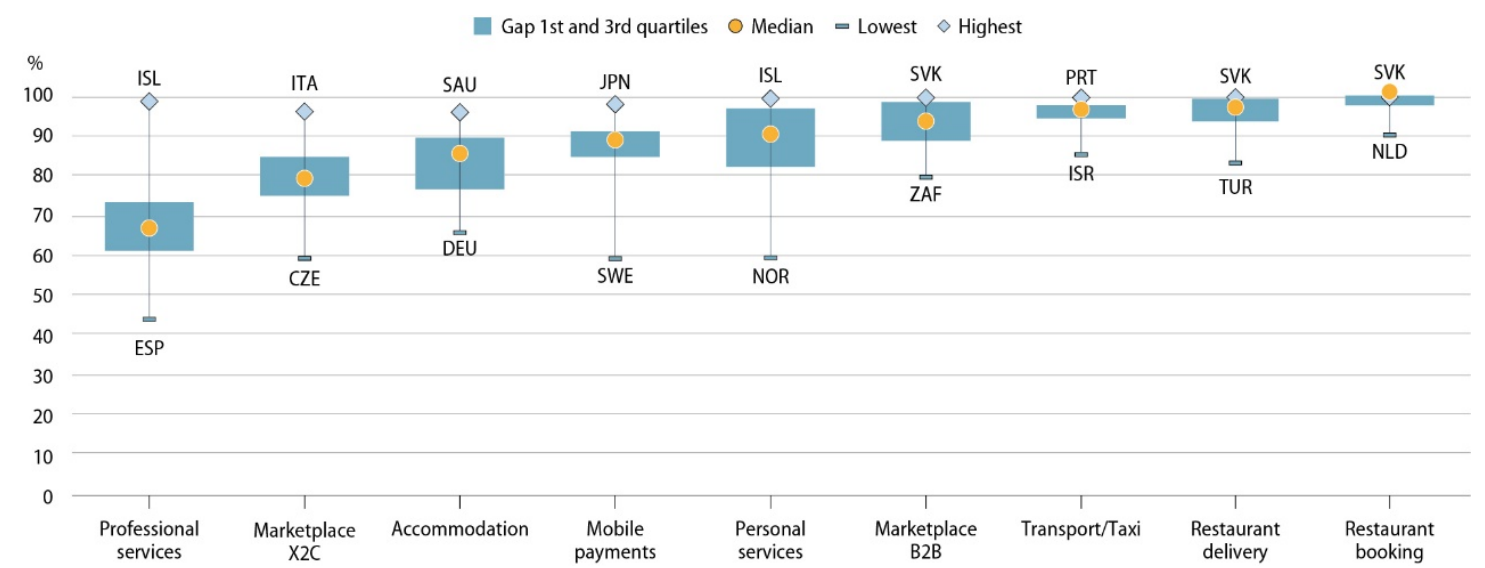

B. Change in the country median of the share of traffic of the four largest platforms, 2016-2019

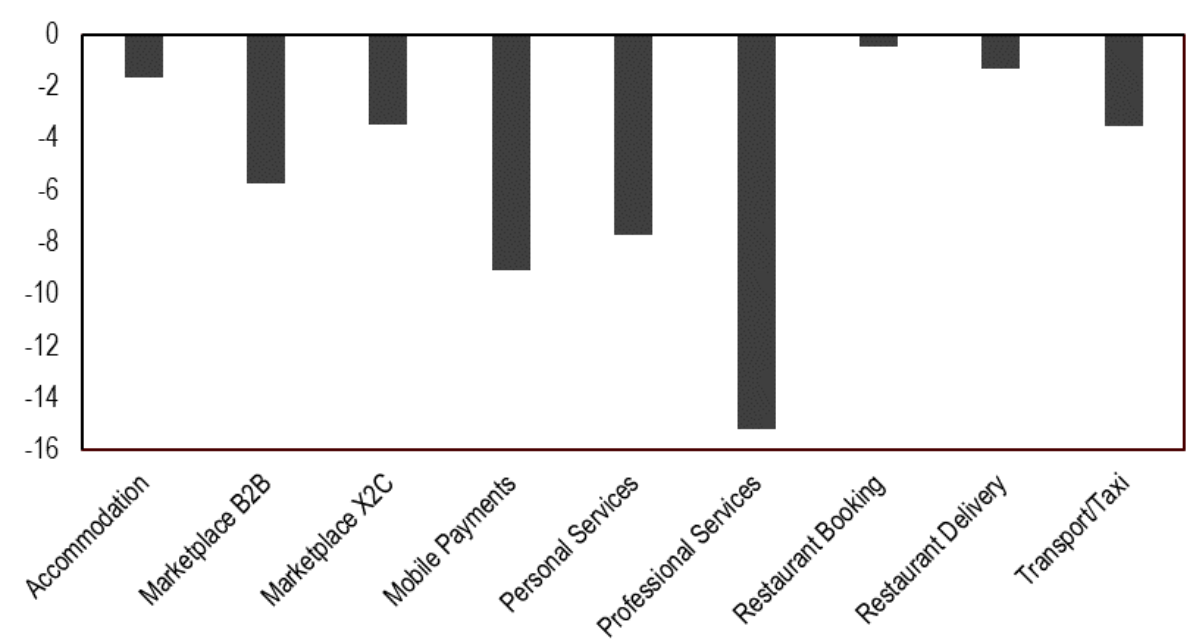

Source: OECD calculations with data from Semrush and Crunchbase. 


\section{Box 4. A bird's-eye view of online platform developments in China}

Over the past decade, Chinese online platforms have developed at a dazzling pace in line with the country's robust economic growth and the rapid adoption of new technologies by vast segments of the population and businesses. The emergence of mobile payment systems in the early 2010 s and their widespread adoption was one of the main driving forces behind China's online platform growth.

As regards mobile payments, China is far ahead of OECD countries. As a share of the population, mobile payments users rose from just above $10 \%$ in 2013 to more than $40 \%$ in 2019. In 2016, the value of China's third-party mobile payments rose to USD 8.8 trillion (50 times the size of the United States' mobile payments). In March 2018, WeChat Pay users alone numbered more than 800 million (OECD, 2019[11]).

One characteristic of mobile payment systems in China is that they have been generally developed by individual platforms to facilitate transactions in their digital marketplaces. For instance, Alibaba has developed Alipay for transactions on Taobao/Tmall whereas JingDong developed JD pay. Initially, each mobile payment system was exclusive to the corresponding platform but over time other online platforms allowed the use of Alipay and other mobile payment systems to settle transactions in their marketplaces.

Most existing Chinese platforms were established in the 2000s and the early 2010s. As in other countries, entry in the transportation sector was problematic because of licenses and occupational regulations. Before the Temporary Administrative Measures for Ride Hailing Services entered into force in 2016, only registered taxis were allowed. *

In China online platforms have gone through a phase of consolidation and exit that has drastically reduced the number of active online platforms. For instance in 2011 there were more than 5000 restaurant booking platforms in China but in 2014 there were just about 180. Tough competition to acquire users have led platforms to offer large price discounts, which proved to be too costly for most platforms forcing them to exit or merge. In general only platforms that could offer large discounts for a long time could survive. Currently there are only a few dozens of platforms in each area of activity. Consolidation has taken place also through M\&As (such as the acquisition by Didi of Uber's Chinese business) and in many cases the relevant competition enforcement agencies have not intervened.

According to some industry analysis, as a large percentage of Chinese population is already using online platforms it will be difficult for new platforms to enter and challenge dominant ones as the costs of acquiring users would be prohibitive (Lei Cao, 2018; AnalysysCN, 2019). Over time, the industry has in certain aspects become more regulated and entry barriers have been raised through for instance price standards. The Administrative Measures for Internet Transaction implemented in 2014 specifies consumer rights and responsibility of providers of any kind of online transaction. ${ }^{* *}$ Consolidation and less competition have allowed online platforms to raise prices, improving profitability. An example comes from the mobile payment platforms as they started to charge transaction fees (as banks do) in $2016^{* * *}$.

As a result of these dynamics, the level of concentration of online platform activity in China is high. The share of market transactions of the top three platforms or top five platforms in the activity areas under analysis where these data were available (all excluding personal and professional services) is usually over $90 \%$.

* Temporary Administrative Measures for Ride Hailing Services(网络预约出租车经营服务管理暂行办) entered into force in $\mathbf{2 0 1 6}$ and mandates that transportation platforms must own a local-government issued license in order to operate in major Chinese cities. 


\section{6}

ECO/CPE/WP1(2020)6

** Administrative Measures for Internet Transaction (网络交易管理办法).

*** Administrative Measures for Non-Bank Payment (非银行支付机构网络支付业务管理办法) entered into force in 2015 regulates mobile payment platforms and set a standard of transfer fee.

Sources: AnalysysCN (2019), 'Growth of OTA platforms slows down'. Available at: http://www.100ec.cn/detail--6508864.html ; Cao Lei (2018), User Growth on E-commerce Platforms Slows Down and Even Becomes Negative, Cost of Acquiring New Clients Becomes the Largest Obstacle, available at: http://news.cyol.com/yuanchuang/2018-09/02/content_17544004.htm; National Bureau of Statistics of China (2020), China Statistics Yearbook 2019, available at: http://www.stats.gov.cn/tisj/ndsi/2019/indexch.htm.

37. The degree of traffic concentration measured for each country and area combination is negatively associated with the degree of internationalisation of online platforms (Figure 10). Thus, if website traffic is a good proxy for platform activity and revenues, a higher degree of internationalisation of online platforms does not appear to reduce competition. Platforms operating in one or few countries are not necessarily small as they have generally a larger volume of traffic than the average platform, and global platforms compete against each other in different countries as well as with large local platforms.

\section{Figure 10. Traffic concentration tends to be lower in sectors with more global platforms}

\section{6-2019}

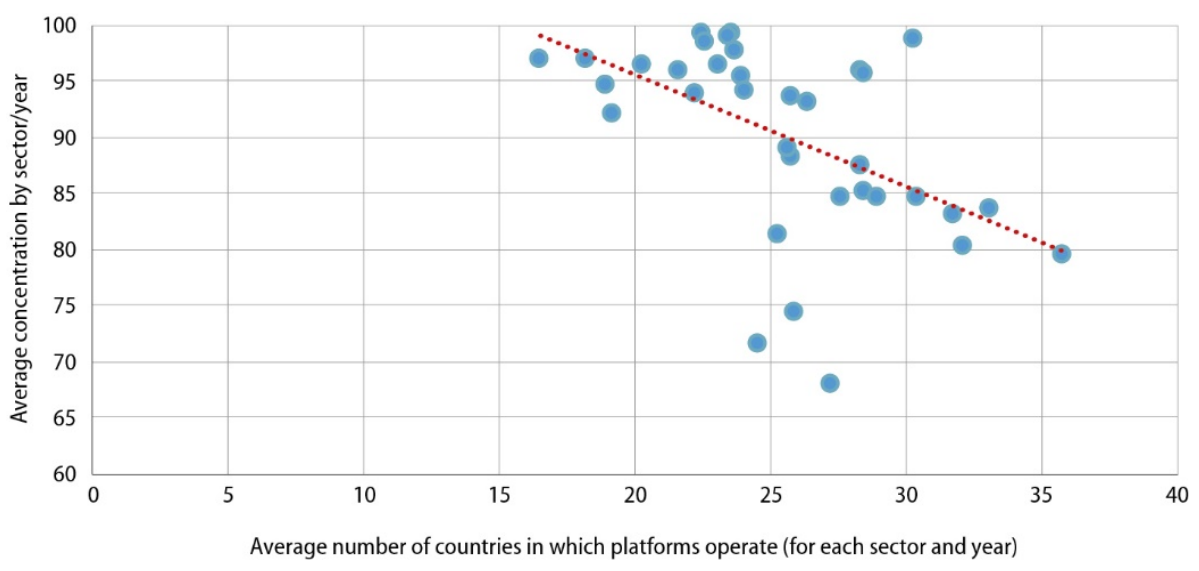

Source: OECD calculations with data from Semrush and Crunchbase.

38. These area concentration figures do not represent market concentration, and even high market concentration does not necessarily imply market power or, even less, abuse of market power. Even very concentrated markets can be highly contestable if new entry is easy and competition for the market is high. This is especially relevant in industries that are young and are evolving fast, such as some digital marketplaces. In markets where there are low sunk costs of entry and marginal costs, along with low or zero users' switching costs, new platforms may be able to gain market shares rapidly, challenging established platforms and leading rapidly to significant changes in industry structure. ${ }^{15}$ The threat posed by smaller platforms can however be the chief reason of so-called killer acquisitions by dominant platforms (OECD, 2020[34]). The OECD has been investigating this and other competition related issues that online platforms raise, such as big data, algorithms and consumer data rights (Box 5).

\footnotetext{
15 This has been the case with rapid increases in users of Bolt and Kapten when Uber's licence was not renewed in London in November 2019 (Boscia, 2019[58]) (Katwala, 2019[59]).
} 


\section{Box 5. Selected OECD work on online platforms and competition}

The Competition Committee has discussed in different meetings and publications key implications of online platforms' activities for competition policy, focusing on issues such as big data, algorithms and consumer data rights. One fundamental issue is how to adapt traditional competition tools to evaluate market power and efficiency in multi-sided digital-platform markets (OECD, 2018[16]). Other studies have focussed on how big data and algorithms might increase market power, thus facilitating anticompetitive behaviour and collusion (even without any formal agreement, i.e. tacit collusion). In this area, discussions have focussed on whether or not competition laws and agencies should consider big data as an asset that can be used to enhance market power and engage in anticompetitive behaviour and on the need for closer cooperation between competition, data protection and consumer policy authorities (OECD, 2016 $\left.{ }_{[17]}\right)$,. On algorithms and collusion, OECD work has analysed whether competition agencies should update the traditional concepts of agreement and tacit collusion as algorithms have the potential to pose substantial risks to competition, though precise data are still missing. It also raises the questions of whether or not there is a need to regulate algorithms and what effects such a policy could have on competition and innovation algorithms (OECD, 2017[18]). The Competition Committee has also looked at consumer data rights and competition, which include traditional rights to privacy but also new ones such as data portability and the right to be forgotten. Theoretically, effective competition should result in higher levels of privacy and control of (or payment for) personal data for consumers. Yet, this is not always the case, especially when consumers do not engage with consumer data rights, perhaps because of behavioural biases or a perceived lack of options. A recent OECD study on consumer data rights (OECD, 2020[19]) concludes that, in cases involving consumer data, competition enforcement should take into consideration privacy and data protection outcomes in co-operation with government agencies responsible for data protection, consumer policy and enforcement. Other relevant recent work has focused on competition in digital advertising markets (OECD, 2020[33]), abuse of dominance in digital markets (OECD, 2020[34]), and the role of line of business restrictions in enabling competition in downstream markets (OECD, 2020[33]).

\section{Structural and policy drivers of platform diffusion}

39. Given the potentially positive effects of platform development on productivity, it is important to understand why platform diffusion differs so greatly across countries and sectors. We therefore turn to the factors that may explain these differences, which in turn can indirectly shape firms' productivity performance in different countries.

40. The analysis is divided in two parts. We first focus on the role played by the structural characteristics of both countries and platforms in explaining their diffusion and uptake. We then explore the link between structural policies and platform diffusion, and how this relationship also depends on platform characteristics. Figure 11 provides a simple taxonomy of the potential drivers of platform diffusion and Table 4 summarises our findings. Aside from platform characteristics, the main variables considered in the analysis are:

- Countries'structural characteristics, including socio-economic and demographic dimensions (such as income levels, share of young people and the share of self-employed as a proxy for the level of entrepreneurship), digital preparedness (the availability of digital infrastructure and digital skills) and platform traffic concentration in the various sectors.

- Structural policies, covering three broad areas: 1) freedom and rule of law; 2) product market regulation; 3 ) digital services regulation. The first area captures the quality of public governance 
and institutions. ${ }^{16}$ The second area includes different types of product market regulations that may hamper or encourage market transactions made possible by online platforms. The third area covers specific regulation of digital services.

\section{Figure 11. Taxonomy of variables affecting platforms' diffusion and uptake}

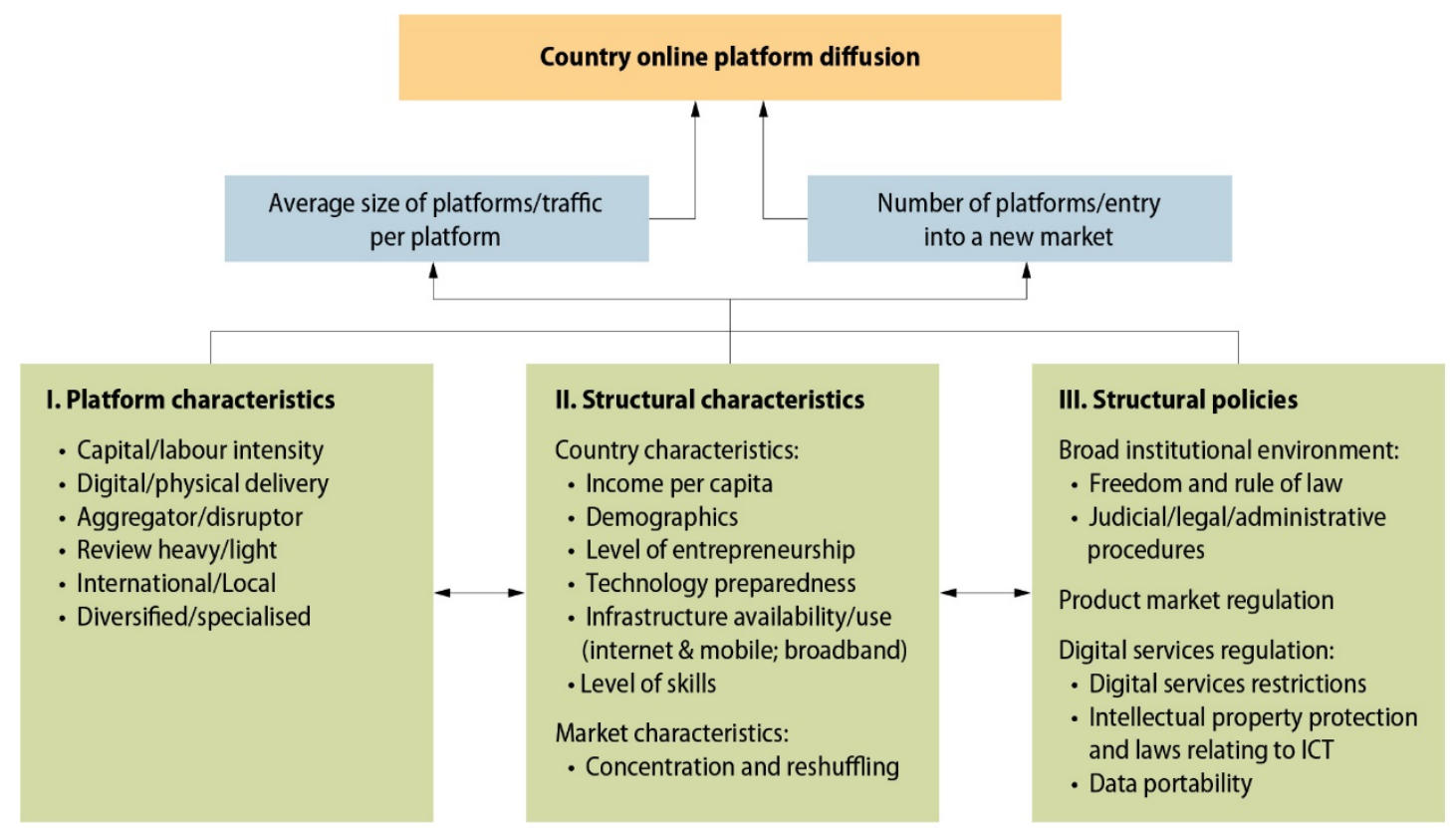

Source: OECD.

41. The relationship between regulations and the development of online platforms is complex. On the one hand, regulation stifling dynamism and increasing costs for businesses can hamper platforms' development (OECD/STI, 2019 $\left.{ }_{[48]}\right)$. For instance, administrative burdens on startups can make entry of new platforms difficult, restrictions on digital trade or data exchanges can weaken market opportunities for platforms and stringent employment protection rules can make the cost of hiring and firing prohibitive, curbing experimentation by innovative platforms. On the other hand, as the existing regulatory framework has been mostly designed for traditional business models (Calvino, Criscuolo and Menon, 2016[49]), the same legal or regulatory rigidities can generate opportunities for some online platforms to circumvent these restrictions by exploiting legal loopholes and uncertainties in their interpretation and application. For instance, online platforms may provide a way for workers lacking formal qualifications and licences to circumvent restrictive occupational entry restrictions (e.g. Uber vs taxi) or employment protection legislation that limits their job opportunities in traditional sectors and activities. Which of these channels will prevail is an empirical question, and it is worth noting that the ability to exploit legal loopholes may diminish over time as governments reform regulations to address such loopholes. In addition, the relationship between regulations and platform development may vary across platforms, depending on their characteristics (as some type of platforms may be more exposed to regulatory restrictions than others).

42. Empirically, we use two approaches interchangeably (see Box 6 for methodological details):

\footnotetext{
${ }^{16}$ A large literature, spawned by the seminal contribution of Mauro (1995[52]) and Acemoglu, Johnson and Robinson $\left(2001_{[56]}\right)$, has shown the important role of these variables for investment, innovation and growth.
} 
- We relate country-level structural characteristics and policies to aggregate (country-level) traffic generated by platforms decomposing total traffic into the average size of platforms (i.e. intensive margin) and the number of platforms (i.e. extensive margin).

We relate platform characteristics to platform-level data on traffic and entry, investigating to what extent these characteristics mediate the effect of policies on online platform traffic and platform decisions to start activities in new countries.

\section{Box 6. The drivers of platform diffusion: empirical strategy}

The empirical strategy follows two main approaches. First, we focus on aggregate (country-level) online platform traffic, decomposing it into multiplicative margins: the average traffic per platform (i.e. the intensive margin) and the number of platforms (i.e. the extensive margin):

$$
\ln \left(\text { Total traffic } c_{c, t}\right)=\ln \left(\text { Average traffic } c_{c, t}\right)+\ln \left(\text { Number of platforms } s_{c, t}\right)
$$

Distinguishing the effect of policies and country characteristics across the two margins sheds light on the channels through which these characteristics and policies affect platform diffusion (as proxied by website traffic). In turn, this can inform the policy debate surrounding platform developments (e.g. concerning potential competition issues).

Based on this identity and using the log of total traffic, average traffic, and number of platforms as dependent variables, we run the following basic regression:

$$
\ln \left(\text { dependent } \text { var }_{c, t}\right)=\beta_{1} \text { Characteristics }_{c, t}+\beta_{2} \text { Policy }_{c}+\theta_{t}+\epsilon_{t, c}
$$

This exercise identifies the association at macro level between traffic, its two margins and countries' characteristics and policies. We estimate the regressions controlling for all structural characteristics at the same time while the policy variables are introduced one by one to avoid collinearity issues. We include time fixed effects (to control for unobserved and common time specific shocks) but not country fixed effects as most of the country characteristics and policy variables vary only across countries.

Second, we focus on platform-level data and study the effects of platform characteristics and policies on traffic of the average platform as well as on entry by new platforms. Country characteristics are still (implicitly) allowed to influence platform traffic via country-time fixed effects. In this case, the impact of policies cannot be identified in isolation as policy variables (which only vary over countries and time at best) are captured by these fixed effects. Therefore, we identify the covariation of traffic with policies via interactions with the platform characteristics that are most likely to mediate the policy influences. The empirical model is the following:

$$
\begin{aligned}
& \ln (\text { traffic or entry })_{i, t, c, s} \\
& \quad=\alpha+\beta_{1} \text { Category }_{i, c, s}+\beta_{2} \text { Policy }_{c} x_{\text {Category }}{ }_{i, c, s}+\beta_{3} C_{t-1, c, s}+\theta_{c t} \\
& +\delta_{s}+\epsilon_{i, t, c, s}
\end{aligned}
$$


where dependent variables are, in turn the traffic of platform $i$, at time $t$, in country $c$ and sector $s$ (traffic $c_{i, t, c, s}$ ) and a dummy variable equal to 1 if platform $i$, at time $t$ and sector $s$ is active in country $c$, and 0 otherwise (entry,i,t,c,s). Category $y_{i, c, s}$ is a vector of time-invariant platform-level characteristics as defined in Section 2, which include the degree of capital/labor intensity, physical/digital delivery, aggregator/disruptor, review intensity, sector diversification and degree of internationalization. $C_{t-1, c, s}$ is a measure of concentration (measured by the share of traffic of the top four and eight platforms in each area) or turnover (measured by the persistence of top eight platforms - the average number of years the top eight platforms in each sector-country-year remain in the top eight - and by the degree of reshufling - the overall change in ranking of top eight firms) in sector $s$ country $c$ and year $t-1$. In regressions used to study the impact of concentration on traffic and entry we exclude the firms in the top four or top eight to lessen reverse-causality issues. Policy ${ }_{c}$ denotes the policies that might affect digital-platform traffic. Policies are interacted with the specific characteristics of the Category vector, which work as an exposure variable in the spirit of Rajan and Zingales (1998). We interact each platform characteristic with selected policy variables that are likely to be mediated by it (see Figure A.2 in Annex A for examples of the links between categories and policies), but when we study just market and platform characteristics we do not include the interactions with policy variables. Finally, $\theta_{c t}$ are countryyear fixed effects and $\delta_{s}$ are sector fixed effects, which account for unobservable characteristics along these two dimensions, and $\epsilon_{i, t, c, s}$ is the error term. We estimate these equations by OLS with standard errors clustered at the country level.

Comparing the results of equations (3) and (4) requires a number of caveats. First, the classic aggregation problem makes it difficult to reconcile quantitatively estimates obtained at the macro and micro level. Second, at the country/macro level results are likely to reflect the direct effects of countries' policies and characteristics on online platforms plus other factors such as strategic interactions among online platforms and the industrial structure (the importance of each sector) of the country as well as the type of platforms operating in each country. ${ }^{*}$ The effects on digital-platform traffic of such strategic choices are likely to be captured by the country-level analysis but not by the platform-level analysis. In addition, since the effects of policies are likely to vary across platforms based on their characteristics, the country-level results also reflect the distribution of such characteristics across countries.

* For instance, the way online platforms targets start-up for acquisitions is increasingly attracting the attention of competition authorities. Recent work has shown that in some cases acquisitions of start-ups are in fact killer acquisitions, lessening potential competition and harming consumers (OECD, 2020[34]).

43. It is important to note at the outset that, while the analysis makes the best of the available data, it only identifies associations between the process of platform diffusion and policies or country and platform characteristics rather than causal relationships. The latter would require a more in depth evaluation of detailed and country-specific policy changes, which is beyond the scope of this study. ${ }^{17}$

\footnotetext{
17 A forthcoming analysis will investigate the impact of the demonetisation that has taken place in India in 2016 on mobile payments and online platform use.
} 


\section{Table 3. Summary of results on platform diffusion}

Variables
Platform characteristics
Digital delivery (5) / Physical delivery
Review Heavy (5) / Review Light (1)
Capital intensive(5)/Labour intensive(1)
Aggregator (5) /Disruptor (1)
International (43) / Local (1)
Diverse (3) / Specialized (1)
Structural characteristics
GDP per capita (\$PPP)
Population
Share of 25-54 year old
Share of self-employed
Broadband diffusion (Fixed)
Skills readiness
Digital adoption index
Concentration (CR4)
Concentration (CR8)
Turnover at the top: Persistence
Turnover at the top: Reshuffling
Structural policies
Rule of law (WB indicator)
Control of corruption (WB indicator)
Judicial independence (1-7)
Efficient legal challenging reg. (1-7)
Cost to enforce contracts (1-7)
IP protection (1-7)
Product Market Regulation (OECD ind.)
Adm. burdens on start-ups (OECD ind.)
Entry barriers in services (OECD ind.)
Occupational entry regul. (OECD ind.)
Regulations in retail (OECD ind.)
Protection of reg. contract (OECD ind.)
Protection of temp.contract (OECD ind.)
Cross border data portability (1-6)
State control over the internet (0-4)
Commercial presence require. (1-0)
Regulation of E-commerce (OECD ind.)

\begin{tabular}{|c|c|c|c|c|}
\hline \multicolumn{3}{|c|}{ Country-level results } & \multicolumn{2}{|c|}{ Platform-level results } \\
\hline Total traffic & $\begin{array}{l}\text { Average traffic } \\
\text { per platform }\end{array}$ & $\begin{array}{l}\text { Number of } \\
\text { platforms }\end{array}$ & $\begin{array}{c}\text { Traffic of average } \\
\text { platform } \\
\\
\mathbf{+ + +} \\
\mathbf{+ + +} \\
\mathbf{+} \\
\text { Not stat. sig. } \\
\mathbf{+ + +} \\
\mathbf{+ + +}\end{array}$ & $\begin{array}{r}\text { Entry of } \\
\text { platforms } \\
\\
+++ \\
+++ \\
+ \\
++ \\
+++ \\
+++\end{array}$ \\
\hline $\begin{array}{l}+++ \\
+++\end{array}$ & $\stackrel{+}{+++}$ & $\begin{array}{l}+++ \\
+++\end{array}$ & & \\
\hline $\begin{array}{l}\text { Not stat. sig. } \\
\text { Not stat. sig. } \\
\text { Not stat. sig. } \\
\mathbf{+ + +}\end{array}$ & $\begin{array}{l}\text { Not stat. sig. } \\
\text { Not stat. sig. } \\
\text { Not stat. sig. } \\
\mathbf{+ +}\end{array}$ & $\begin{array}{r}\text { Not stat. sig. } \\
\text { Not stat. sig. } \\
\mathbf{+ + +} \\
\text { Not stat. sig. }\end{array}$ & & \\
\hline Not stat. sig. & Not stat. sig. & & $\begin{array}{c}-- \\
\text { Not stat. sig. } \\
\mathbf{+ +}\end{array}$ & $\begin{array}{l}\text { Not stat. sig. } \\
\text { Not stat. sig. } \\
\text { Not stat. sig. } \\
\text { Not stat. sig. }\end{array}$ \\
\hline $\begin{array}{r}\mathbf{+ + +} \\
\mathbf{+ + +} \\
\mathbf{+ + +} \\
\text { Not stat. sig. } \\
\text { Not stat. sig. } \\
\text { Not stat. sig. }\end{array}$ & $\begin{array}{c}\mathbf{+ + +} \\
\mathbf{+ +} \\
\text { Not stat. sig. } \\
- \\
\text { Not stat. sig. } \\
\text { Not stat. sig. }\end{array}$ & $\begin{array}{r}+++ \\
+++ \\
+++ \\
+++ \\
++ \\
++\end{array}$ & & \\
\hline Not stat. sig. & Not stat. sig. & $\begin{array}{l}\text { Not stat. sig. } \\
\text { Not stat. sig. }\end{array}$ & + Disruptor;+ Rev.Heavy & + Disruptor \\
\hline Not stat. sig. & Not stat. sig. & $=$ & & \\
\hline Not stat. sig. & Not stat. sig. & - & & \\
\hline $\begin{array}{l}\text { Not stat. sig. } \\
\text { Not stat. sig. }\end{array}$ & $\begin{array}{c}\text { Not stat. sig. } \\
\mathbf{+}\end{array}$ & $=$ & & \\
\hline $\begin{array}{r}+++ \\
+++ \\
++\end{array}$ & $\begin{array}{c}\mathbf{+ + +} \\
\text { Not stat. sig. } \\
\mathbf{+ +}\end{array}$ & $\begin{array}{r}\text { Not stat. sig. } \\
\mathbf{+ + +}\end{array}$ & +International & \\
\hline Not stat. sig. & Not stat. sig. & $\ldots$ & & \\
\hline
\end{tabular}

Note: The symbols represent the sign of the estimated coefficient of the characteristic/policy variable in country-level regressions (columns 13 ), and platform-level regressions (columns 4-5), or of the interaction with platform characteristics (columns 4-5), as described in Box 6. One +/symbol indicates the coefficient is statistically significant at the $10 \%$ level, two indicate $5 \%$ level, and three $1 \%$ level. "Not stat. sig." indicates a statistically insignificant coefficient.

Source: OECD estimations with data from Semrush, and Crunchbase.

\subsection{Platform diffusion depends on both platform and country characteristics}

\subsubsection{Platform characteristics}

44. We find that platform characteristics play an important role in explaining differences in diffusion (as measured by traffic) and entry (as measured by the number of platforms). Overall, platforms relying more on digital service or product delivery, those using review and rating systems more intensively and those operating in more countries and more sectors tend to generate more traffic than the others (Figure 12, panel A). There is also evidence, albeit statistically weaker, that capital-intensive platforms are larger than labour intensive ones. The same type of platforms (plus aggregators) are also more likely to enter new countries more frequently than the others (Figure 12, panel B). 


\section{Figure 12. Platform characteristics and diffusion}

Panel A. Association of characteristics with platform-level traffic

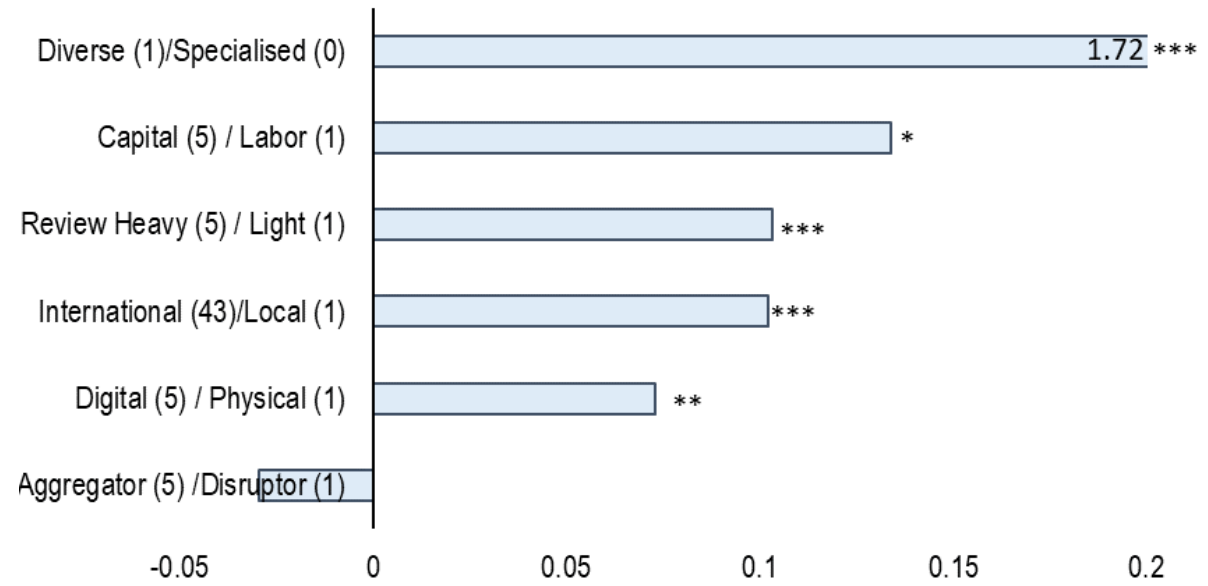

Panel B. Association of characteristics with platforms' entry in a new country

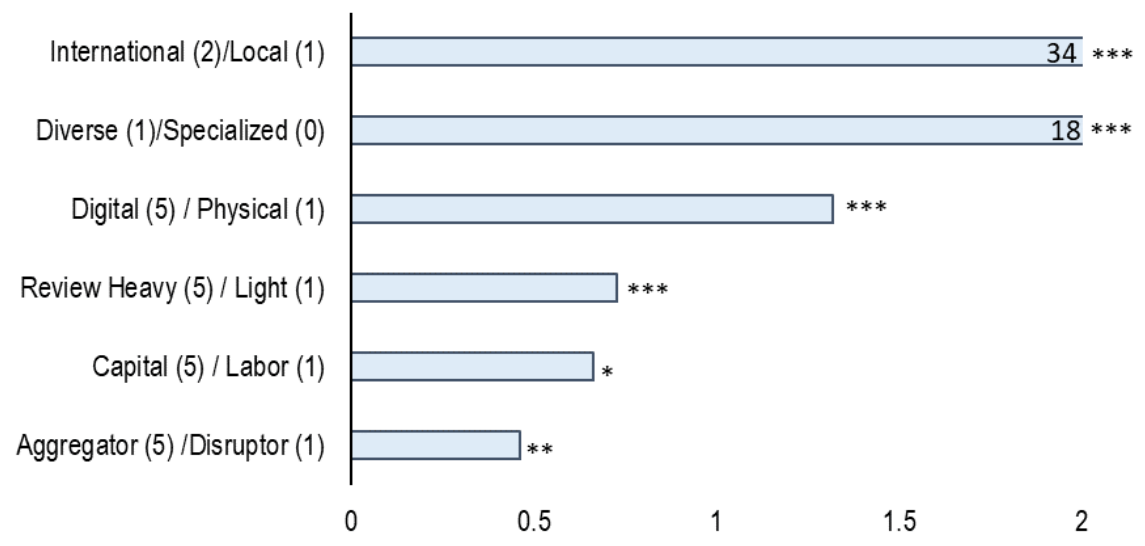

Note: Stars denote statistical significance: ${ }^{* * *} 1 \%,{ }^{* *} 5 \%,{ }^{*} 10 \%$. In panel $\mathrm{A}$, the bars represent the percentage increase, normalised to a $0-1$ scale, in the average size of platforms (computed as the total number of visits to all platforms' websites over total number of platforms) associated with an increase of one unit in the classification of platforms. In panel B, the bars represent the increase, in the probability of the average platform entering an additional country associated with an increment of one unit in the classification of platforms. The horizontal axes are capped, for the sake of clarity, and values at the end of the bars denote outliers. Results are based on equation (4) in Box 6 without the interaction term: $\ln \left(\right.$ traffic $_{i, t, c, s}=\alpha+\beta_{1}$ Category $_{i, c, s}+\beta_{3} C_{t-1, c, s}+\theta_{c t}+\delta_{s}+\epsilon_{i, t, c, s}$ (Panel A); $\ln (\text { traffic })_{i, t, c, s}=\alpha+\beta_{1}$ Category $_{i, c, s}+$ $\beta_{3} C_{t-1, c, s}+\theta_{c t}+\delta_{s}+\epsilon_{i, t, c, s}$ (Panel B). All regression include country-year and sector fixed effects. Standard errors clustered at the country level. Full regression in column (3) (Panel A) and column (11) (Panel B) of Table B.2 of Annex B. Diverse platforms are those operating in two or three areas of activity and specialised platforms are those operating in one area of activity. In Panel $A$ the level of intenationalisation is a continuous variable reflecting the number of countries (from 1 to 43) the platform operates on and in Panel $B$ it is a dummy variable equal to 1 if the platform operates in 5 or more countries and zero otherwise. Diverse platforms are those operating in two or three areas of activity and specialised platforms are those operating in one area of activity.

Source: OECD estimations with data from Semrush, and Crunchbase.

45. These results are consistent with the following observations:

- Online platforms providing review and rating systems fill information gaps concerning service quality between buyers with sellers. This lessens the danger of mismatch between expected and actual quality, favouring market exchanges and magnifying cross-group network effects (Belleflamme and Peitz, 2018[33]). This is highlighted by the rise and success of some online 
platforms (such as Airbnb, Amazon, or Booking.com) that build trust between parties by eliciting and posting a large number of reviews and ratings by users.

- Platforms relying more on digital service delivery can scale up operations more easily, as (i) they are unconstrained by the quality of the physical transport network they operate in and (ii) face lower entry costs because they do not need to establish logistic centres or even a physical presence in the new country.

- Platforms that are more globalised and diversified have more leeway to exploit the scale and scope economies involved in data collection and analysis across different geographic and activity areas.

- The initial cost of complying with labour market regulations might be lower for those platforms relying on capital rather than labour intensive goods or services delivery.

\subsubsection{Structural characteristics}

46. Countries' characteristics in terms of income, demographics, and digital preparedness are likely to affect the uptake and diffusion of platforms. Moreover, the structure of platform markets, as captured by concentration and dynamism, can also play an important role in platform diffusion. Results, presented in Figure 13, suggest the following main points:

- GDP per capita: Online platforms are more developed in countries with higher income (as measured by the PPP GDP per capita) as consumers' purchasing power determines the volume of transactions taking place in online marketplaces (as in more traditional markets). The increase in online platform activity (as estimated by total traffic) associated with higher income is mostly accounted for by the size of platforms $(60 \%)$ rather than the number of platforms $(40 \%)$. This is consistent with the descriptive statistics presented in Section 2 pointing to larger and richer countries having bigger platforms.

- Population: Online platforms are more developed in countries with a large population. As with GDP per capita, the effect on online platform development takes place mostly through the average size of platforms and to a lesser extent through the number of platforms. This pattern underlines the importance of network effects as this is to a large extent driven by platforms attracting a larger number of users (thus becoming larger) rather than by an increasing number of platforms.

- Broadband penetration: Countries with more fixed broadband connections per inhabitant tend to have a larger number of platforms. Specifically, an increase from the $25^{\text {th }}$ to the $75^{\text {th }}$ percentile of broadband coverage per ten inhabitants in the sample is associated with a $16 \%$ increase in the number of platforms. This is indicative that the quality of communication infrastructure promotes the creation of online. Broadband penetration does not seem to have a significant effect on the size (i.e. volume of activity) of online platforms. These results are consistent with the hypothesis that quality communication infrastructure is a necessary condition for platforms to start operating in a country.

- Skills readiness: Countries with better digital skills tend to have more developed online platforms. The estimates suggest that going from the $25^{\text {th }}$ percentile of the observed skills readiness index to the $75^{\text {th }}$ percentile is associated with a $53 \%$ increase in platform traffic. This effect is attributable to the size of platforms but not to the number of platforms, suggesting that digital skills promote a more intense use of online platforms.

- Concentration and dynamism: Across countries, platform-level traffic is negatively associated with the level of traffic concentration while it is positively associated with the degree of reshuffling among the largest platforms (Figure 13, Panel B). These findings suggest that high concentration of online platform activity tends to slow down online platforms' growth, resulting in smaller 
platforms. On the contrary, more dynamism in the form of high turnover at the top is associated with larger platforms on average.

\section{Figure 13. Structural characteristics and platform diffusion}

Panel A. Association of countries' characteristics with total platforms' website traffic, average website traffic per platform and number of platforms

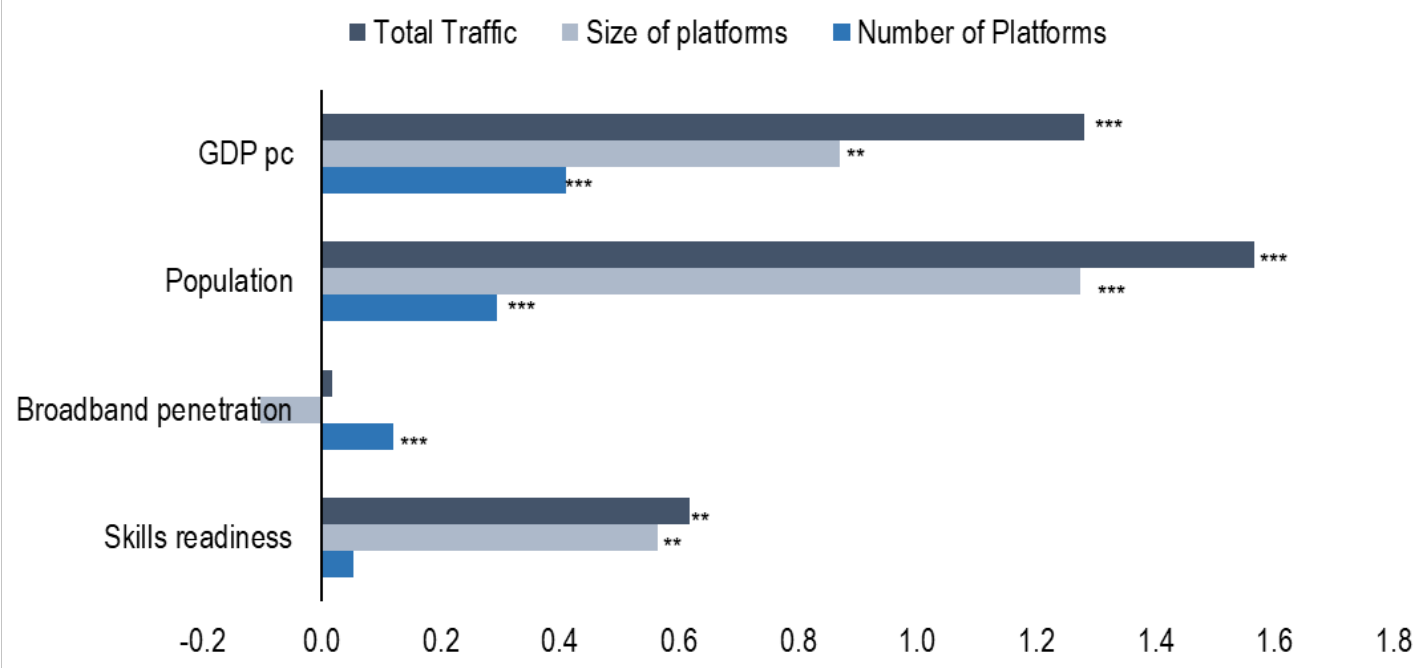

Panel B. Association of concentration and turnover of the largest platforms with platform-level traffic

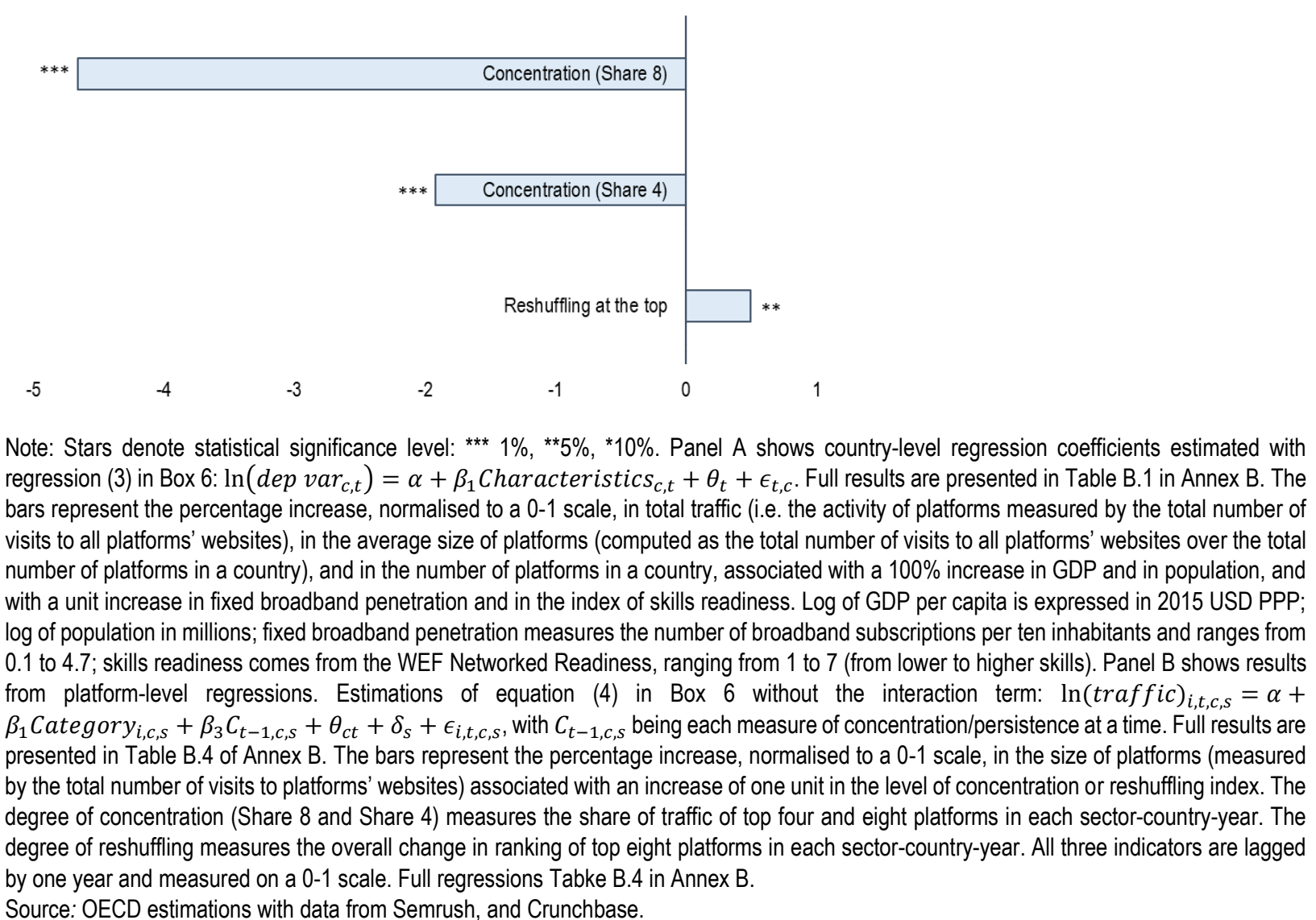

Source: OECD estimations with data from Semrush, and Crunchbase. 
47. Taken together these results indicate that digital preparedness, in terms of both skills and infrastructure, and online platform market dynamism are important factors facilitating platform diffusion. This is consistent with previous studies (Andrews, Nicoletti and Timiliotis, 2018[34]) showing that adequate skills and connectivity are pre-conditions for adopting digital technologies as well as with concerns related to the consequences of winner-take-most phenomena for technology diffusion. Policies to improve access to infrastructure and digital skills as well as to ensure market openness are therefore important to promote the take up of online platforms. These and other relevant policies are discussed below.

\subsubsection{Structural policies}

\section{Policies for enhancing communication infrastructure}

48. As highlighted by the results in Figure 13 and previous research (Nicoletti, von Rueden and Andrews, $\left.2020_{[35]}\right)$, access to communication infrastructure and their quality are a key enabler of the use of digital technologies including online platforms. Recent data suggest that coverage and quality of broadband connectivity still vary greatly across OECD and G20 countries (OECD, 2020[36]). For instance, in 2019 , in Korea and Japan about $80 \%$ of fixed broadband connections were fibre connections against less than $5 \%$ in Germany and United Kingdom. There is also great variation in the access to and quality of communication networks within countries. Usually people in remote areas have significantly worse access to communication networks than urban populations (OECD, 2018[37]).

49. Several good practices to promote digital connectivity exist within and between countries. On a general level, governments need to invest directly in high-speed communication networks or improve incentives for private enterprises to invest, especially in rural and remote places (OECD, 2018[37]). Specific policies can involve voucher programmes and targeted subsidies, competitive tenders for private-sector network deployment, tax exemptions, low-interest loans, lower spectrum fees, implementing open access and infrastructure-sharing arrangements and a supportive regulatory environment. For instance, Korea has achieved high broadband penetration rates earlier than other countries due to a mix of supply and demand side policies including: highly competitive markets, clear strategic plans and financing schemes guiding public direct investment, incentives for private investment (e.g., low interest loans for network rollout in rural areas), free internet access centres in remote areas, and a responsive regulatory approach responsive to changing market conditions.

50. Enhancing wireless communication networks can be especially important for online platforms' diffusion as the use of online-platform services often takes place through mobile devices. Building $5 \mathrm{G}$ mobile networks will require the deployment of many small $5 \mathrm{G}$ nodes and their backhaul connections, which may need the approval of myriad of agencies at local level. Thus, streamlining administrative procedures - for instance to secure "rights of way" to dig up streets - will expedite such processes. For example, Germany has taken measures to strengthen coordination of civil works across municipalities. By defining presumptively reasonable time for local authorities to grant or deny different permit applications, the United States' Federal Communication Commission can substantially accelerate the pace of 5G deployment. The development of $5 \mathrm{G}$ wireless networks depends also on the efficient allocation of the spectrum while infrastructure sharing can help to mitigate investment costs (OECD, 2019 [38]; OECD, 2020[36]).

51. Policies to widen access to communication infrastructure are discussed more in detail OECD (2021 forthcoming ${ }_{[50]}$ ) and in OECD contributions of the Infrastructure Working Group. Ongoing OECD work is focusing on developing guidelines for financing digital infrastructure., which will build on the update of the Recommendation of the OECD Council on Broadband Development (OECD, 2004 [40]), and on reports dealing specifically with bridging territorial divides in connectivity, and developing and maintaining high quality networks and connectivity. 


\section{Policies for enhancing digital skills}

52. The results presented above support the idea that using online platforms requires the right set of skills. The adoption and effective use of digital technologies relies on three broad sets of skills: (i) ICT generic skills enabling the handling of basic digital tasks (e.g. navigating the internet, using emails, using general software); (ii) complementary soft skills, including management, communication or teamwork skills; and (iii) technical and professional ICT skills. The use of most online platforms is likely to require ICT generic skills along with complementary soft skills ( $\mathrm{i}$ and ii above). Investment in these skills is likely to be crucial for platform development (OECD, 2019[41]). For example, companies in Germany identify shortage of skilled labour as a deterrent for offering and developing online platforms and other digital business models (vbw, 2019 $\left.9_{[42]}\right)$

53. Between and within countries there are large differences in the skills dimensions that matter for online-platform use. For example, in the United Kingdom, over $70 \%$ of individuals between 16 and 64 perform many and complex activities online, but less than half of the population in Italy do so. There are also large differences within countries as older individuals and those with lower education and income levels are less likely to use online platforms, a difference that has been increasing over time (OECD, $\left.2019_{[43]}\right)$. Promoting the use of platforms across all layers of society requires improving lifelong learning systems through better adult learning and school systems. Improving adult learning systems can enlarge the productivity benefits arising from online platforms as these are higher for small and micro enterprises (OECD, 2021 [1]). Platform workers, small entrepreneurs and their employees often have less (or lack altogether) formal training than those in larger enterprises - especially in less advanced countries - and many of them may lack the capabilities to move their operations online. For SMEs, using platforms is less demanding in terms of skills than other digital technologies, and many larger platforms offer free online courses and tutorials catered specifically to SMEs. However, in order to take advantage of online platforms, they need adequate internal digital processes requiring investment in basic digital and organisational skills (OECD, 2021[44]).

54. Targeted financial incentives can support training in basic digital skills. Governments can also play an important role in providing training and information specific to the use of platforms. For instance, the United Kingdom has launched the E-Exporting Programme to assist firms planning to expand sales overseas through online marketplaces (and other e-commerce channels). The French government has built an inventory of online platforms providing help to SMEs in developing commercial websites, navigating marketplaces and using payment.

55. Finally, the simple accessibility of online platforms, while a key determinant of their success, heightens the risk that many users (both small entrepreneurs and consumers) lack the digital and financial literacy preventing misuse and digital crime. In this area, developing policies following the G20/OECD Policy Guidance on Financial Consumer Protection Approaches in the Digital Age and G20/OECD INFE Policy Guidance on Digitalisation and Financial Literacy would help to develop transparent and fair online financial services platforms and build trust in digital financial and payment methods. Governments need to ensure that digital financial services follow a robust financial consumer protection framework, including the availability of educational tools for digital payment users (consumers and entrepreneurs) through a variety of delivery channels to reduce exclusion.

\section{Policies to ensure openness of platform markets}

56. The results shown in Figure 13 also point to the role of market contestability in promoting online platforms' growth. Different strategic choices of large platforms could explain these results, such as the killer acquisitions of smaller platforms. Studies investigating the issue of killer acquisitions have found that incumbent dominant companies may acquire smaller innovative competitors with high growth potential just to discontinue their innovative products or services and neutralise the competitive threats they pose (Cunningham, Ederer and Ma, 2021 $[45]$ ). If this type of acquisitions happen early on in the development 
process of acquired companies, the market may become populated by large incumbent companies along with smaller ones with low growth prospects and posing no real threat to the dominant ones. Killer acquisitions have raised concerns among competition enforcement agencies as the welfare losses due to reduced competition, innovation and product/service variety may offset the efficiency gains such acquisitions generate (OECD, 2020[29]).

57. As showed in (Costa et al., forthcoming ${ }_{[58]}$ ), online-platform market contestability matters for the productivity-growth effects online platforms have on incumbent companies. The positive association between online platform activity the productivity growth of incumbent firms tends to be stronger the higher the degree of reshuffling among the largest online platforms (i.e. the higher the contestability of onlineplatform markets). Thus, ensuring that online-platform markets remain open and contestable will be beneficial to the development of online platforms in addition to widening their benefits by accelerating the productivity growth on incumbent companies. The companion background paper of this study discusses these issues more in detail (OECD, 2021 [1]).

\section{Policies affecting the digital business environment}

58. A number of other policies affecting the digital business environment are associated with the diffusion of platforms. These include both framework and regulatory policies in product and labour markets and more regulations in the area of digital services.

\section{Framework policies}

59. First, the quality of institutions (as measured by rule of law, corruption control and judicial independence or efficiency) is positively associated with the development of online platforms. This is in line with the large literature linking institutional quality with innovation and economic performance (e.g. Mauro (1995[46]), Acemoglu and Robinson (2010[7]), Silve and Plekhanov (2018[6]). The link between the rule of law indicator and country-level online platforms' traffic is rather strong. The point estimate suggests that, other things equal, raising the rule of law indicator from the $25^{\text {th }}$ percentile to the $75^{\text {th }}$ percentile in the sample would more than double online platform activity. (Figure 14 and Table D.3 in Annex D). The quality of institutions is mostly linked to total platform traffic via the average size of platform, except for the level of judicial independence, for which the link is driven by the number of platforms.

60. Platforms also tend to be more numerous in countries with more efficient judicial procedures (Figure 14 and Table B.3 in Annex B), perhaps because online platforms might prefer to start operating in countries where they can efficiently challenge the application of those laws and regulations that they consider unwarranted. 


\section{Figure 14. Quality of institutions and platform diffusion}

Association of different indicators with total platforms' website traffic, average website traffic per platform and number of platforms

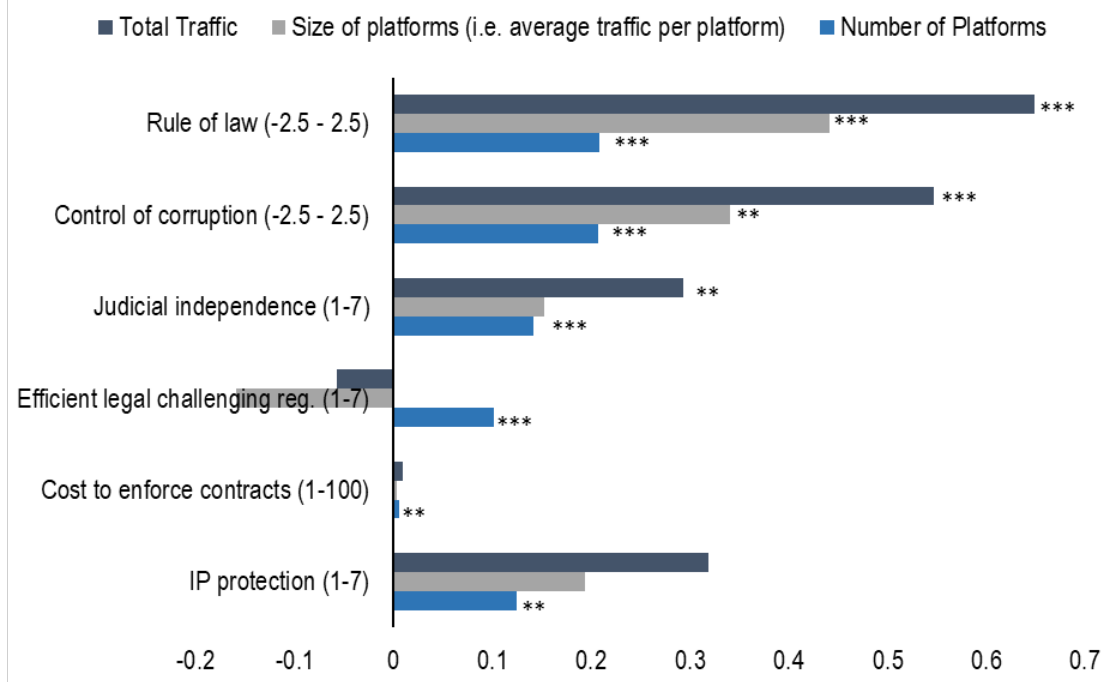

Note: Significance level at which the null hypothesis is rejected: ${ }^{* * *} 1 \%,{ }^{* *} 5 \%,{ }^{*} 10 \%$. Coefficients are estimated with regression (3) in Box 6 , with each of the policies in turn. Full results are presented in Table B.3 in Annex B. The bars represent the percentage increase, normalised to a 0-1 scale, in total traffic (i.e. the activity of platforms measured by the total number of visits to all platforms' websites), in the average size of platforms (computed as the total number of visits to all platforms' websites over the total number of platforms in a country), and in the number of platforms in a country, associated with an increase of one unit in each of the indicators. The indicators for rule of law and control of corruption are sourced from World Bank's Worldwide Governance indicators, and range from -2.5 to 2.5. The indicators for judicial independence, efficient legal challenging regulation, and IP protection are sourced from the WEF Networked Readiness and range from 1 to 7 . The cost to enforce contracts is an indicator of the time it takes to resolve commercial disputes from the World Bank's Doing Business indicators, ranging from 0 to 100.

Source: OECD estimations with data from Semrush, and Crunchbase.

61. The costs of enforcing contracts are positively associated with the number of online platforms. As many online platforms offer free intermediation services to help parties to solve disputes out of court, incentives to start activity in digital market places might be especially strong in countries with high contractenforcement costs. ${ }^{18}$ According to an OECD survey (OECD, 2017 $[47]$ ), more than $50 \%$ of heavy platform users experienced problems with counterparts on online platforms. Resolution however was reached in the majority of cases and only a tiny minority of users who experienced problems ultimately reported stopping using platforms.

62. The predictable and fair enforcement of laws and regulations, the protection of private property rights, and an independent and well-resourced system of justice and regulatory authorities encourage valuable market exchanges inherent in the platform economy, through lower uncertainty and higher trust. Trust, in particular, is critical to the acceptability and use of digital platforms, which rely on the sharing of often confidential and personal data by consumers.

63. Institutions promoting transparency, fair process and accountability can also buttress policy experimentation and transparent stakeholder in new and dynamic areas, including online platforms. Because of the pervasiveness and complexities of online platforms, however, designing new effective policies from scratch is challenging. Pilot projects and policy experimentation are more promising ways of

\footnotetext{
${ }^{18}$ These free intermediation services can be especially convenient to SMEs and in small-claim cases for which going to courts would be too expensive and take too long.
} 
designing effective policies in this context (Lesher, 2020 [48]; Attrey, Lesher and Lomax, 2019 [49]). These can take the form of regulatory sandboxes and other structured policy experimentation approaches including class waivers for eligible products, leniency for testing and piloting and innovation hubs (Zetzsche et al., 2017[50]; Buckley et al., 2020[51]).

64. Finally, the results also suggest that better protection of intellectual property rights are associated with wider online platform diffusion. The positive association between the strength of intellectual property rights and the number of platforms is not surprising as platforms involve a large degree of innovation or novel entrepreneurial or organisational practices, and many studies have shown that strong protection of intellectual property rights boosts innovation (Kanwar and Evenson, 2003[52]; Papageorgiadis and Sharma, $\left.2016_{[53]}\right)$.

\section{Product and labour market regulations}

65. The results also show that regulatory barriers to entry in services and network sectors are negatively associated with total online platforms' activity (Figure 15 and Table B.3 in Annex B). This is consistent with the idea that more open and competitive services markets will encourage service providers to adopt new technologies to survive and prosper relative to rivals (Nicoletti, von Rueden and Andrews, $\left.2020_{[8]}\right)$. More specifically, restrictions relating to occupational licensing for personal services are negatively associated with online platforms' activity, in line with findings that restrictive licensing curbs efficiency improvements (Bambalaite, Nicoletti and von Rueden, 2020[54]). Finally, platforms appear to prosper more in countries with lighter employment protection legislation (EPL), mainly via the number of platforms, perhaps due to the implied lower labour costs for hiring both temporary and regular workers.

\section{Figure 15. Regulation, licensing and platform diffusion}

Association of different indicators with total platforms' website traffic, average website traffic per platform and number of platforms

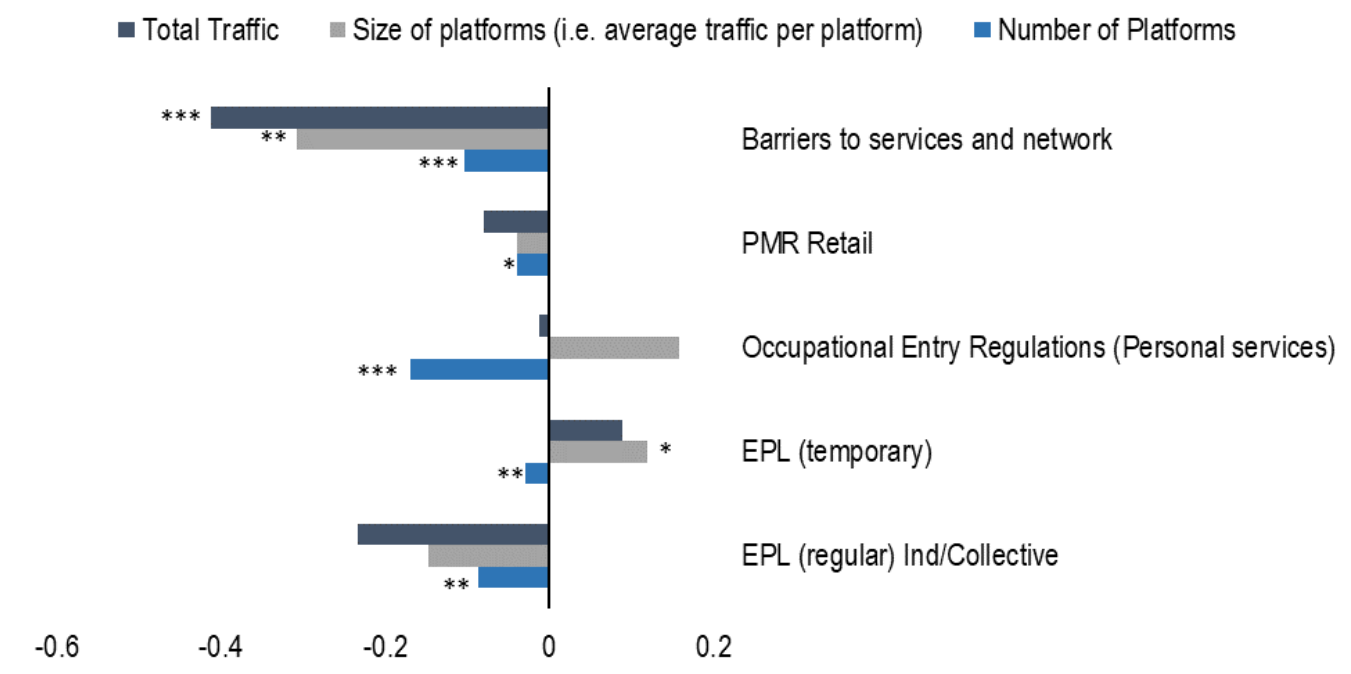

Note: Significance level at which the null hypothesis is rejected:*** $1 \%$, ${ }^{* *} 5 \%,{ }^{*} 10 \%$. Coefficients are estimated with the regression (3) in Box 6 , with each of the policies in turn. Full results are presented in Table B.3 of Annex B. The bars represent the percentage increase, normalised to a 0-1 scale, in total traffic (i.e. the activity of platforms measured by the total number of visits to all platforms' websites), in the average size of platforms (computed as the total number of visits to all platforms' websites over the total number of platforms in a country), and in the number of platforms in a country, associated with an increase of one unit in each of the indicators. Barriers to services and networks, Product Market Regulation (PMR) Retail, Occupation Entry Regulations (Personal Services), Employment Protection Legislation (EPL) (temporary) and EPL (regular) are OECD indicators and range from 0 to 6 .

Source: OECD estimations with data from Semrush, and Crunchbase. 
66. These results should be nuanced highlighting the complex relationship between market regulations and the development of online platforms. On the one hand, as discussed regulation stifling dynamism and increasing costs for businesses can curb experimentation by innovative platforms and hamper their development (OECD/STI, 2019 $\left.9_{[55]}\right)$. On the other hand, as the existing regulatory framework has been mostly designed for traditional business models (Calvino, Criscuolo and Menon, 2016 ${ }_{[56]}$ ), the same legal or regulatory rigidities can generate opportunities for some online platforms to circumvent these restrictions by exploiting legal loopholes and uncertainties in their interpretation and application. For instance, online platforms may provide a way for workers lacking formal qualifications and licences to circumvent restrictive occupational entry restrictions (e.g. Uber vs taxi) or employment protection legislation that limits their job opportunities in traditional sectors and activities.

\section{$\underline{\text { Regulation of digital services }}$}

67. Lastly, the results show the association between policies that are specific to digital services and online platform diffusion (Figure 16). For instance, countries where internet is free from state control tend to have a higher diffusion of online platforms and fewer restrictions on e-commerce tend to stimulate online platforms' activity. Both freer internet and easier e-commerce are associated with a larger number of platforms.

Conversely, the requirement to establish a commercial presence is associated with wider online platform diffusion. One interpretation is that this requirement raises the costs of establishing a physical presence in a country, implying that only large platforms (or platforms likely to have many users) will establish operations there. In other words, because of these additional fixed costs only large platforms might choose to entry countries with commercial presence requirements. This is consistent with the finding that commercial presence requirements affect particularly the size of platforms that deliver mostly physical services, for which this self-selection mechanism is more pronounced as (compared to digital delivery platforms) commercial presence requires setting logistic centres and warehouses.

\section{Figure 16. Regulation of digital services and platform diffusion}

Association of different indicators with total platforms' website traffic, average website traffic per platform and number of platforms

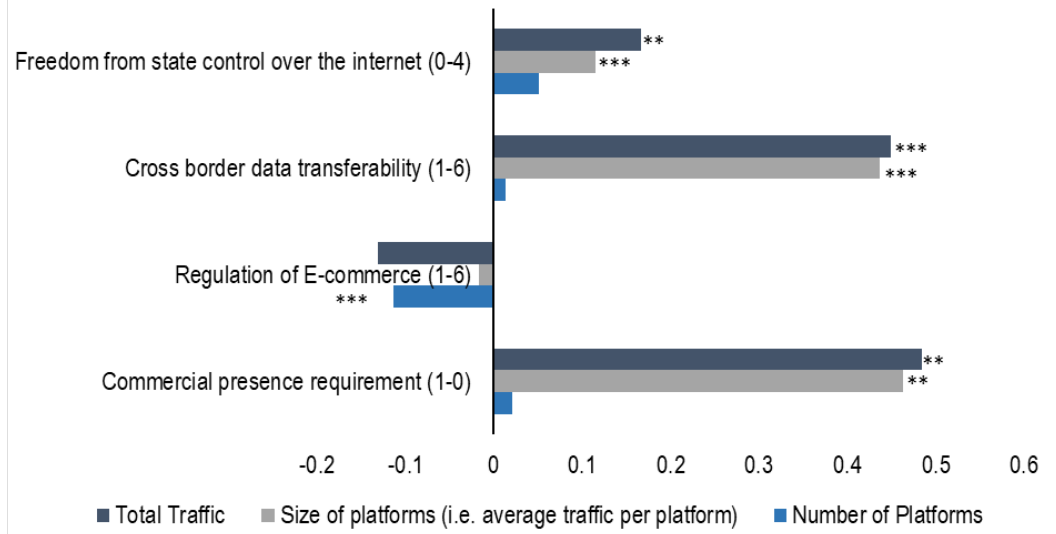

Note: Significance level at which the null hypothesis is rejected: ${ }^{* *} 1 \%,{ }^{*} 5 \%,{ }^{*} 10 \%$. Coefficients are estimated with regression 3 in Box 6 , with each of the policies in turn. Full results are presented in Table B.3, Annex B. The bars represent the percentage increase, normalised to a 0-1 scale, in total traffic (i.e. the activity of platforms measured by the total number of visits to all platforms' websites), in the average size of platforms (computed as the total number of visits to all platforms' websites over the total number of platforms in a country), and in the number of platforms in a country, associated with an increase of one unit in each of the indicators. The indicator of Freedom from state control over the internet is sourced from the Fraser Institute and ranges from 0 to 4 . Cross border data transferability is an OECD indicator and measures the easiness with which data can be transferred across borders and ranges from 0 to 6 . Regulation of E-commerce is an indicator of the strictness of market regulation pertaining to electronic transactions compiled by the OECD and ranges from 0 to 6 . Commercial presence requirements is a dummy 
variable available from the $\mathrm{OECD}$ equal to 1 if platforms are required to have a commercial presence in order to operate in a given country. Source: OECD estimations with data from Semrush, and Crunchbase.

68. Restrictions to cross-border data transferability may also hinder the diffusion of online platforms and restrict competition. Online platforms indeed tend to be larger in countries with fewer restrictions on cross-border data transferability. Given the high degree of internationalisation of most online platforms the ease with which online platforms can transfer data across jurisdictions is an important factor for scaling up platform activity. Consistent with this, international platforms are found to enjoy stronger activity levels than domestic platforms the higher the value of the cross-border data transferability freedom index (Figure 17).

69. However, data flows across jurisdictions raise several concerns relating to privacy protection, data security and data integrity, regulatory control or audit, national security and digital industrial policies. Such concerns have led countries to update their data-related policies in recent years, often placing conditions on the transfer of data across borders or requiring that data be stored locally. The number of these restrictive policies doubled in the past 10 years (Ferracane, Kren and van der Marel, 2018[57]; World Economic Forum, 2020[58] $)$. A high profile example of these restrictions was the "Schrems II" decision in mid-2020, in which the European Court of Justice deemed the "Privacy Shield" to be an inadequate mechanism for transferring personal data between the European Economic Area and the United States. The multiplicity of applicable data regimes creates uncertainty for governments, businesses and individuals, including with regard to the applicable rules in a given situation. This can impose prohibitively high compliance and entry costs on small platforms, by forcing them to build or lease data centres and comply with different local data regulations. Limiting the flow of data across borders can also curtail the ability of countries to detect and monitor fraud and money laundering (World Economic Forum, 2020[59]).

\section{Figure 17. Cross border data transferability affects differently international and local platforms}

Effects on platforms' website traffic of being an international platform (versus being a local one) for different level of cross-border data transferability

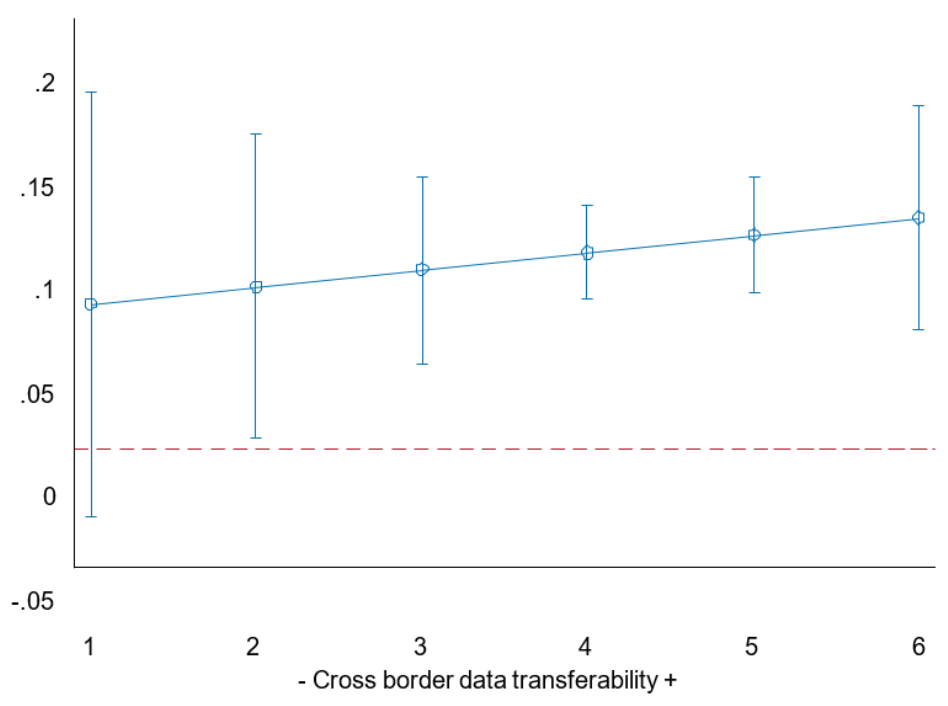

Note: The vertical bars represent the $95 \%$ confidence interval of the estimated marginal effects represented by the middle dots. The estimated marginal effects represent the percentage increase, normalised to the 0-1 scale, in the average size of platforms (computed as the total number of visits to all platforms' websites over the total number of platforms) associated with a platform switching from being local to being international (i.e. present in five countries or more) and computed for different values of the cross border data transferability indicator. Marginal effects are estimated with regression (4) in Vox 6, where Category stands for the number of countries platforms are active in (ranging from 1 to 43 ) and CBDP is the indicator for cross border data transferability.

Source: OECD estimations with data from Semrush, and Crunchbase. 
70. Progress in this area relies on promoting cross-border data transferability without undermining data privacy and security. Implementing internationally recognised security standards and best practices in online security would boost trust in other countries' security standards and reduce cybersecurity risks, thereby encouraging cross-border data transfer (OECD, 2020[36]). At the same time, instruments to strengthen cybersecurity help build trust in digital technology and as such can be an important tool for diffusion (OECD, 2020[36]). This is currently acquiring increasing importance also because digital security risk is increasing as malicious actors take advantage of the coronavirus (COVID-19) epidemic (OECD, 2020[62]).

71. Privacy and data protection standards are crucial for the use of platforms, where large quantities of personal, business, and financial information are relayed and traded. Yet most users, especially individuals and SMEs, lack the skills to understand the scale and scope of the data they share (OECD, $\left.2021_{[44]}\right)$. Increasing digital security and privacy therefore requires a coordinated government approach, encompassing regulation of different actors, monitoring, increased awareness, skill development, and tax incentives (ENISA, 2020[63]).

\section{Conclusion}

72. Despite their rising importance in modern economies, debates surrounding online platforms have been mired in a paradoxical situation: although online platforms are adept at collecting and exploiting vast quantity of data, available data on their operations, diffusion and impacts on economies and societies are scarce and inconsistent. National accounts poorly capture the economic activities taking places in digital marketplaces (OECD, 2018[8]) and policy discussions are often based on anecdotal evidence and selected data released by online platforms themselves.

73. This paper contributes to policy discussions surrounding the diffusion of online platforms in three main ways. First, it builds a new harmonised international dataset on of global and local platforms across 43 OECD and G20 countries, covering the 2013-19 period and nine activity areas. Second, it describes main trends, and third, it investigates the structural and policy determinants of online platforms diffusion across countries and over time. The findings bear several policy implications, laid down in Section 4.

74. As a larger share of economic activity shifts towards online platforms it will be crucial to provide policy makers precise evidence on how policies affect platforms with different characteristics. This research is all the more important in view of the role that online platforms (especially those not relying on physical contact) are playing in cushioning the effects of the current COVID-19 crisis (OECD, 2020[4]). Pursuing efforts to collect better and cross-country comparable data on online platform operations is crucial in this respect. The causal evaluation of policies on online platform activity will require to identify clear policy changes and the mechanisms through which different types of platforms may be affected and to use formal policy evaluation and event study analyses. This may require linking the activity of people and firms in online platforms with various economic and social outcomes through administrative data. 


\section{References}

Acemoglu, D. and J. Robinson (2010), "The Role of Institutions in Growth and Development", Review of Economics and Institutions, Vol. 1/2, http://dx.doi.org/10.5202/rei.v1i2.14.

Andrews, D., G. Nicoletti and C. Timiliotis (2018), "Digital technology diffusion: A matter of capabilities, incentives or both?", OECD Economics Department Working Papers, No. 1476, OECD Publishing, Paris, https://dx.doi.org/10.1787/7c542c16-en.

Attrey, A., M. Lesher and C. Lomax (2019), The role of sandboxes in promoting flexibility and innovation in the digital age, Going Digital Toolkit Policy Note, No. 2., https://goingdigital.oecd.org/toolkitnotes/the-role-of-sandboxes-in-promoting-flexibility-andinnovation-in-the-digital-age.pdf (accessed on 19 February 2021).

Bailin Rivares, A. et al. (2019), "Like it or not? The impact of online platforms on the productivity of incumbent service providers", OECD Economics Department Working Papers, No. 1548, OECD Publishing, Paris, https://dx.doi.org/10.1787/080a17ce-en.

Bambalaite, I., G. Nicoletti and C. von Rueden (2020), "Occupational entry regulations and their effects on productivity in services: Firm-level evidence", OECD Economics Department Working Papers, No. 1605, OECD Publishing, Paris, https://dx.doi.org/10.1787/c8b88d8b-en.

Belleflamme, P. and M. Peitz (2019), "Managing competition on a two-sided platform", Journal of Economics \& Management Strategy, Vol. 28/1, pp. 5-22, http://dx.doi.org/10.1111/jems.12311.

Belleflamme, P. and M. Peitz (2018), "Inside the Engine Room of Digital Platforms: Reviews, Ratings, and Recommendations", Working Papers, Aix-Marseille School of Economics, Vol. WP 2018 Nr 06, https://halshs.archives-ouvertes.fr/halshs-01714549 (accessed on 28 July 2020).

Bernard, A. and B. Jensen (1995), "Exporters, Jobs, and Wages in U.S. Manufacturing: 19761987", Brookings Papers on Economic Activity, https://www.brookings.edu/bpeaarticles/exporters-jobs-and-wages-in-u-s-manufacturing-1976-1987/ (accessed on 23 September 2020).

Bernard, A., S. Redding and P. Schott (2011), "Multiproduct firms and trade liberalization", Quarterly Journal of Economics, Vol. 126/3, pp. 1271-1318, http://dx.doi.org/10.1093/qje/qjr021.

Brynjolfsson, E. et al. (2007), "Scale without mass: business process replication and industry dynamics", Proceedings Nov, https://ideas.repec.org/a/fip/fedfpr/y2007inovx13.html (accessed on 15 July 2020). 
Buckley, R. et al. (2020), "Building Fintech Ecosystems: Regulatory Sandboxes, Innovation Hubs and Beyond", Washington University Journal of Law \& Policy, Vol. 61/1, https://openscholarship.wustl.edu/law journal law policy/vol61/iss 1/10 (accessed on 19 February 2021).

Calvino, F., C. Criscuolo and C. Menon (2016), "No Country for Young Firms?: Start-up Dynamics and National Policies", OECD Science, Technology and Industry Policy Papers, No. 29, OECD Publishing, Paris, https://dx.doi.org/10.1787/5jm22p40c8mw-en.

Costa, H. et al. (2021), "Are online platforms killing the offline star? Platform diffusion and the productivity of traditional firms", OECD Economics Department Working Papers, No. 1682, OECD Publishing, Paris.

Cunningham, C., F. Ederer and S. Ma (2021), "Killer Acquisitions", Journal of Political Economy, pp. 000-000, http://dx.doi.org/10.1086/712506.

Dawson, J. (1998), "Institutions, investment, and growth: New cross-country and panel data evidence", Economic Inquiry, Vol. 36/4, pp. 603-619, http://dx.doi.org/10.1111/j.14657295.1998.tb01739.x.

ENISA (2020), Good practices under the National Cyber Security Strategies, https://www.enisa.europa.eu/news/enisa-news/good-practices-under-the-nationalcybersecurity-strategies (accessed on 8 January 2021).

Farronato, C. et al. (2020), "Consumer Protection in an Online World: An Analysis of Occupational Licensing", National Bureau of Economic Research Working Paper Series, Vol. No. 26601, http://dx.doi.org/10.3386/w26601.

Ferracane, M., J. Kren and E. van der Marel (2018), The cost of data protection, Vox EU CEPR, https://voxeu.org/article/cost-data-protectionism.

Helpman, E., M. Melitz and S. Yeaple (2004), "Export versus FDI with heterogeneous firms", American Economic Review, Vol. 94/1, pp. 300-316, http://dx.doi.org/10.1257/000282804322970814.

IFO (2020), Industrial digital economy - B2B platforms, https://english.bdi.eu/publication/news/Industrial-digital-economy-B2B-platforms/.

Kanwar, S. and R. Evenson (2003), "Does intellectual property protection spur technological change?", Oxford Economic Papers, Vol. 55/2, pp. 235-264, http://dx.doi.org/10.1093/oep/55.2.235.

Lane, M. (2020), "Regulating Platform Work in the Digital Age", Going Digital Toolkit Policy Note, No. No 1, OECD, https://goingdigital.oecd.org/toolkitnotes/regulating-platform-workin-the-digital-age.pdf (accessed on 21 September 2020).

Lesher, M. (2020), Sandboxes and the role of policy experimentation, https://voxeu.org/article/sandboxes-and-role-policy-experimentation (accessed on 19 February 2021).

Mauro, P. (1995), "Corruption and Growth", The Quarterly Journal of Economics, Vol. 110/3, pp. 681-712, http://dx.doi.org/10.2307/2946696.

Nicoletti, G., C. von Rueden and D. Andrews (2020), "Digital technology diffusion: A matter of 
capabilities, incentives or both?", European Economic Review, Vol. 128, p. 103513, http://dx.doi.org/10.1016/i.euroecorev.2020.103513.

Nicoletti, G., C. von Rueden and D. Andrews (2020), "Digital technology diffusion: A matter of capabilities, incentives or both?", European Economic Review, Vol. 128, p. 103513, http://dx.doi.org/10.1016/i.euroecorev.2020.103513.

OECD (2021), Harnessing the producitivty benefits of online platforms: Backgrond paper, OECD contribution to the Framework Working Group of the 2021 G20 Presidency.

OECD (2021), The Digital Transformation of SMEs, OECD Studies on SMEs and Entrepreneurship, OECD Publishing, Paris, https://doi.org/10.1787/bdb9256a-en.

OECD (2020), Abuse of Dominance in Digital Markets, http://www.oecd.org/daf/competition/abuse-of-dominance-in-digital-markets-2020.pdf (accessed on 30 November 2020).

OECD (2020), Competition in Digital Advertising Markets, http://www.oecd.org/daf/competition/competition-in-digital-advertising-markets-2020.pdf (accessed on 30 November 2020).

OECD (2020), Consumer Data Rights and Competition - Background Note, OECD Publishing, Paris, https://www.oecd.org/daf/competition/consumer-data-rights-and-competition.htm (accessed on 30 August 2020).

OECD (2020), Dealing with digital security risk during the Coronavirus (COVID-19) crisis, OECD Policy Responses to Coronavirus (COVID-19), http://www.oecd.org/coronavirus/policy-responses/dealing-with-digital-security-risk-duringthe-coronavirus-covid-19-crisis-c9d3fe8e/.

OECD (2020), Line of business restrictions as a solution to competition concerns - OECD, http://www.oecd.org/daf/competition/line-of-business-restrictions-as-a-solution-tocompetition-concerns.htm (accessed on 30 November 2020).

OECD (2020), Model Rules for Reporting by Platform Operators with respect to Sellers in the Sharing and Gig Economy, OECD Publishing, Paris, https://www.oecd.org/tax/exchangeof-tax-information/model-rules-for-reporting-by-platform-operators-with-respect-to-sellersin-the-sharing-and-gig-economy.htm (accessed on 30 August 2020).

OECD (2020), OECD Digital Economy Outlook 2020, OECD Publishing, Paris, https://dx.doi.org/10.1787/bb167041-en.

OECD (2020), OECD/G20 Inclusive Framework on BEPS: Progress Report July 2019-July 2020, OECD Publishing, Paris, http://www.oecd.org/tax/beps/oecd-g20-inclusiveframework-on-beps-progress-report-july-2019-july-2020.htm (accessed on 30 August 2020).

OECD (2020), Start-ups, Killer Acquisitions and Merger Control, http://www.oecd.org/daf/competition/start-ups-killer-acquisitions-and-merger-control.htm (accessed on 9 September 2020).

OECD (2020), The Role of Digital Platforms in Weathering the COVID-19 Shock, ECO/CPE/WP1(2020)19. 
OECD (2019), An Introduction to Online Platforms and Their Role in the Digital

Transformation, OECD Publishing, Paris, https://dx.doi.org/10.1787/53e5f593-en.

OECD (2019), Enhancing Access to and Sharing of Data: Reconciling Risks and Benefits for Data Re-use across Societies, OECD Publishing, Paris, https://dx.doi.org/10.1787/276aaca8-en.

OECD (2019), "Measuring Platform Mediated Workers", OECD Digital Economy Papers, No. 282, OECD Publishing, Paris, https://dx.doi.org/10.1787/170a14d9-en.

OECD (2019), Measuring the Digital Transformation: A Roadmap for the Future, OECD Publishing.

OECD (2019), OECD Employment Outlook 2019: The Future of Work, OECD Publishing, Paris, https://dx.doi.org/10.1787/9ee00155-en.

OECD (2019), OECD Skills Outlook 2019 : Thriving in a Digital World, OECD Publishing, Paris, https://dx.doi.org/10.1787/df80bc12-en.

OECD (2019), "The road to $5 \mathrm{G}$ networks: Experience to date and future developments", OECD Digital Economy Papers, No. No. 284, OECD, https://www.oecd-ilibrary.org/scienceand-technology/the-road-to-5g-networks 2f880843-en (accessed on 13 January 2021).

OECD (2019), Unpacking E-Commerce: Business Models, Trends and Policies, OECD Publishing, Paris, https://doi.org/10.1787/23561431-en.

OECD (2018), "Bridging the rural digital divide", OECD Digital Economy Papers, No. 265, OECD Publishing, Paris, https://dx.doi.org/10.1787/852bd3b9-en.

OECD (2018), Market Concentration, OECD DAF/COMP/WD(2018)46, https://www.oecd.org/daf/competition/market-concentration.htm.

OECD (2018), Measuring online platforms and cloud computing in National Accounts.

OECD (2018), Rethinking Antitrust Tools for Multi-Sided Platforms 2018, OECD Publishing, https://www.oecd.org/daf/competition/rethinking-antitrust-tools-for-multi-sidedplatforms.htm.

OECD (2018), Tax Challenges Arising from Digitalisation - Interim Report 2018: Inclusive Framework on BEPS, OECD/G20 Base Erosion and Profit Shifting Project, OECD Publishing, Paris, https://dx.doi.org/10.1787/9789264293083-en.

OECD (2017), Algorithms and Collusion: Competition Policy in the Digital Age, http://www.oecd.org/competition/algorithms-collusion-competition-policy-in-the-digitalage.htm.

OECD (2017), International VAT/GST Guidelines, OECD Publishing, Paris, https://dx.doi.org/10.1787/9789264271401-en.

OECD (2017), "Trust in peer platform markets: Consumer survey findings", OECD Digital Economy Papers, No. 263, OECD Publishing, Paris, https://dx.doi.org/10.1787/1a893b58en.

OECD (2016), Big Data: Bringing Competition Policy to the Digital Era, OECD, https://one.oecd.org/document/DAF/ COMP(2016)14/en/pdf. 
OECD (2016), "New Forms of Work in the Digital Economy", OECD Digital Economy Papers, Vol. 260, https://dx.doi.org/10.1787/5j|wnklt820x-en.

OECD (2016), "Protecting Consumers In Peer Platform Markets: Exploring The Issues", OECD Digital Economy Papers, No. 253, OECD Publishing, Paris, https://dx.doi.org/10.1787/5jlwvz39m1zw-en.

OECD (2015), Addressing the Tax Challenges of the Digital Economy, Action 1 - 2015 Final Report, OECD/G20 Base Erosion and Profit Shifting Project, OECD Publishing, Paris, https://dx.doi.org/10.1787/9789264241046-en.

OECD (2015), Data-Driven Innovation: Big Data for Growth and Well-Being, OECD Publishing, Paris, https://dx.doi.org/10.1787/9789264229358-en.

OECD (2011), The Role of Internet Intermediaries in Advancing Public Policy Objectives, OECD Publishing, Paris, https://dx.doi.org/10.1787/9789264115644-en.

OECD (2004), Recommendation of the Council on Broadband development, http://www.oecd.org/digital/ieconomy/29892925.pdf (accessed on 25 February 2021).

OECD (2021 forthcoming), Spurring growth and closing gaps through digitalization in a postCOVID world: A menu of policy options to LIFT all boats, OECD Economics Deparmetnt Working Paper.

OECD/STI (2019), Business dynamics and digitalisation, https://www.oecdilibrary.org/science-and-technology/business-dynamics-and-digitalisation 6e0b011a-en (accessed on 5 October 2020).

Panzar, J. and R. Willing (1981), "Economies of Scope", The American Economic Review, Vol. 71/2, pp. 268-72.

Papageorgiadis, N. and A. Sharma (2016), "Intellectual property rights and innovation: A panel analysis”, Economics Letters, Vol. 141, pp. 70-72, http://dx.doi.org/10.1016/i.econlet.2016.01.003.

Schwellnus, C. et al. (2019), "Gig economy platforms: Boon or Bane?", OECD Economics Department Working Papers, No. 1550, OECD Publishing, Paris, https://dx.doi.org/10.1787/fdb0570b-en.

Silve, F. and A. Plekhanov (2018), "Institutions, Innovation and Growth: Cross-Country Evidence”, EBRD Working Paper No. 177, http://dx.doi.org/10.2139/ssrn.3119688.

Treece, F. (1982), "Towards an Economic Theory of the Multiproduct Firm", Journal of Economic Behavior \& Organization, Vol. 3/1, pp. 39-63.

vbw (2019), Plattformen - Infrastruktur der Digitalisierung, http://www.vbw-bayern.de/ (accessed on 4 December 2020).

World Economic Forum (2020), A Roadmap for CrossBorder Data Flows: Future-Proofing Readiness and Cooperation in the New Data Economy, White paper.

World Economic Forum (2020), Exploring International Data Flow Governance, World Economic Forum White Paper, http://www3.weforum.org/docs/WEF Trade Policy Data Flows Report.pdf. 
48 | ECO/CPE/WP1(2020)6

Zetzsche, D. et al. (2017), "Regulating a Revolution: From Regulatory Sandboxes to Smart Regulation", Fordham Journal of Corporate \& Financial Law, Vol. 23/1,

https://ir.lawnet.fordham.edu/icfl/vol23/iss1/2 (accessed on 19 February 2021). 


\section{Annex A. Additional information on data collection}

Table A.1. Platforms across areas of activity

\begin{tabular}{|c|c|c|c|}
\hline \multirow{2}{*}{ Area } & \multirow{2}{*}{$\begin{array}{l}\text { Number of } \\
\text { platforms }\end{array}$} & \multicolumn{2}{|c|}{ Examples } \\
\hline & & Present in many countries & Present in one or few countries \\
\hline Accommodation & 210 & airbnb, booking & lastminute-cottages, triverna \\
\hline Marketplace B2B & 115 & alibaba, indiamart & buyinportugal, luxalia \\
\hline Marketplace X2C & 241 & amazon, ebay & storesquare, trucadao \\
\hline Mobile Payments & 150 & paypal, rakuten & vindi, zoomit \\
\hline Personal Services & 185 & treatwell, taskrabbit & yad2, grupinis \\
\hline Professional Services & 147 & upwork, freelancer & crowdguru, belancer \\
\hline Restaurant Booking & 46 & opentable, zomato & luxtable, lunchgate \\
\hline Restaurant Delivery & 149 & deliveroo, ubereats & clickdelivery, aptit \\
\hline Transport/Taxi & 85 & bolt, uber & apptaxi, m-o-v \\
\hline
\end{tabular}

Note: Some platforms are present in more than one area (e.g. rakuten is present in marketplace to consumer, mobile payments and accommodation; uber is present in transport and restaurant delivery, etc.) so the sum of platforms by area is larger than the total number of unique platforms.

Source: OECD.

\section{Table A.2. Classification specifications}

Capital/labour intensity, digital/physical delivery, aggregator/disruptor; review intensity

\begin{tabular}{|c|c|c|c|c|c|c|}
\hline & 5 & 4 & 3 & 2 & 1 & \\
\hline $\begin{array}{l}\text { Capital } \\
\text { intensive }\end{array}$ & $\begin{array}{r}\text { Platform main } \\
\text { activity requires } \\
\text { mostly (almost } \\
\text { all) capital inputs }\end{array}$ & $\begin{array}{r}\text { Both capital and } \\
\text { labour are } \\
\text { required but } \\
\text { capital is clearly } \\
\text { the largest share }\end{array}$ & $\begin{array}{r}\text { Both capital and labour } \\
\text { are required in seemingly } \\
\text { equal shares }\end{array}$ & $\begin{array}{r}\text { Both capital and } \\
\text { labour are } \\
\text { required but } \\
\text { labour is clearly } \\
\text { the largest share }\end{array}$ & $\begin{array}{r}\text { Platform main activity } \\
\text { requires mostly } \\
\text { (almost all) labour }\end{array}$ & $\begin{array}{l}\text { Labour } \\
\text { intensive }\end{array}$ \\
\hline $\begin{array}{l}\text { Digital } \\
\text { delivery }\end{array}$ & $\begin{array}{r}\text { The good or } \\
\text { service provided } \\
\text { (not the booking) } \\
\text { is delivered fully } \\
\text { digitally }\end{array}$ & & $\begin{array}{r}\text { The platform provides } \\
\text { both goods/services that } \\
\text { are delivered digitally and } \\
\text { that require physical } \\
\text { presence }\end{array}$ & & $\begin{array}{r}\text { The good or service } \\
\text { provided (not the } \\
\text { booking) is delivered } \\
\text { fully physically or a } \\
\text { physical presence is } \\
\text { required }\end{array}$ & $\begin{array}{l}\text { Physical } \\
\text { delivery }\end{array}$ \\
\hline Aggregator & $\begin{array}{r}\text { Platform only } \\
\text { connects existing } \\
\text { providers }\end{array}$ & $\begin{array}{r}\text { Connects mostly } \\
\text { existing providers } \\
\text { but can be used } \\
\text { by new entrants }\end{array}$ & $\begin{array}{r}\text { Both new and existing } \\
\text { providers in equal } \\
\text { numbers }\end{array}$ & $\begin{array}{l}\text { Connects mostly } \\
\text { new entrants but } \\
\text { can be used by } \\
\text { existing providers }\end{array}$ & $\begin{array}{r}\text { Platform only } \\
\text { connects new } \\
\text { entrants with demand }\end{array}$ & Disruptor \\
\hline $\begin{array}{l}\text { Review } \\
\text { heavy }\end{array}$ & $\begin{array}{r}\text { Users on both } \\
\text { sides can be } \\
\text { reviewed with } \\
\text { both a score and } \\
\text { text }\end{array}$ & $\begin{array}{r}\text { Users on one } \\
\text { side only are } \\
\text { reviewed with } \\
\text { both text and } \\
\text { score }\end{array}$ & $\begin{array}{r}\text { Users on both sides can } \\
\text { be review but just with a } \\
\text { score }\end{array}$ & $\begin{array}{l}\text { Users on only } \\
\text { one side can be } \\
\text { reviewed with } \\
\text { just a score }\end{array}$ & $\begin{array}{r}\text { No users on any side } \\
\text { are reviewed }\end{array}$ & $\begin{array}{r}\text { Review } \\
\text { light }\end{array}$ \\
\hline & 5 & 4 & 3 & 2 & 1 & \\
\hline
\end{tabular}

Source: OECD. 
50 | ECO/CPE/WP1(2020)6

Figure A.1. Classification examples of online platforms

\begin{tabular}{|c|c|c|c|c|c|c|}
\hline & 5 & 4 & 3 & 2 & 1 & \multirow{5}{*}{ Labour intensive } \\
\hline \multirow[t]{4}{*}{ Capital intensive } & \multirow[t]{4}{*}{ Apple Pay } & Airbnb & Amazon & Deliveroo & Taskrabbit & \\
\hline & & Booking & Treatwell & Uber & Mturk & \\
\hline & & & Alibaba B2B & & YoupiJob & \\
\hline & & & Zomato & & & \\
\hline \multirow[t]{9}{*}{ Digital delivery } & MTurk & & YoupiJob & & Taskrabbit & \multirow[t]{9}{*}{ Physical delivery } \\
\hline & Apple Pay & & & & Deliveroo & \\
\hline & & & & & Zomato & \\
\hline & & & & & Uber & \\
\hline & & & & & Booking & \\
\hline & & & & & Airbnb & \\
\hline & & & & & Amazon & \\
\hline & & & & & Alibaba B2B & \\
\hline & & & & & Treatwell & \\
\hline \multirow[t]{5}{*}{ Aggregator } & Deliveroo & Booking & Amazon & Airbnb & Taskrabbit & \multirow[t]{5}{*}{ Disruptor } \\
\hline & Zomato & & & & Uber & \\
\hline & Treatwell & & & & YoupiJob & \\
\hline & Apple Pay & & & & MTurk & \\
\hline & Alibaba B2B & & & & & \\
\hline \multirow[t]{8}{*}{ Review heavy } & Airbnb & Taskrabbit & Uber & Mturk & \multirow[t]{7}{*}{ Apple Pay } & \multirow[t]{13}{*}{ Review light } \\
\hline & & Amazon & & Deliveroo & & \\
\hline & & Alibaba B2B & & & & \\
\hline & & YoupiJob & & & & \\
\hline & & Treatwell & & & & \\
\hline & & Zomato & & & & \\
\hline & & Booking & & & & \\
\hline & 5 & 4 & 3 & 2 & 1 & \\
\hline \multirow[t]{5}{*}{ Legend: } & & \multicolumn{2}{|c|}{ Accommodation } & \multicolumn{2}{|c|}{ Professional services } & \\
\hline & & Marketplac & & & Restaurants (booking) & \\
\hline & & \multicolumn{2}{|c|}{ Marketplace to consumers } & & \multirow{3}{*}{$\begin{array}{c}\text { Restaurants (delivery) } \\
\text { Transport }\end{array}$} & \\
\hline & & Mobile payr & & & & \\
\hline & & Personal se & & & & \\
\hline
\end{tabular}

Source: OECD. 


\section{Annex B. Regression Analysis}

Table B.1. Regression results: Platform diffusion and country characteristics

\begin{tabular}{|c|c|c|c|c|}
\hline & & Total Traffic & Average Traffic & Number of Platforms \\
\hline \multirow[t]{2}{*}{ Income per capita } & \multirow{2}{*}{$\begin{array}{l}\text { Log of GDP per capita } \\
\text { (2015 USD PPP) }\end{array}$} & $1.280^{* \star *}$ & $0.870^{* *}$ & $0.409^{\star \star \star}$ \\
\hline & & $(0.373)$ & $(0.357)$ & $(0.0675)$ \\
\hline \multirow{2}{*}{ Demographics } & \multirow{2}{*}{$\begin{array}{l}\text { Log of Population } \\
\text { (in millions) }\end{array}$} & $1.566^{\star \star \star}$ & $1.273^{\star * *}$ & $0.293^{\star * \star}$ \\
\hline & & $(0.0558)$ & $(0.0560)$ & $(0.0143)$ \\
\hline \multirow[t]{2}{*}{ Entrepreneurship } & \multirow{2}{*}{$\begin{array}{l}\text { Share of Self-employed } \\
\text { (\% employment) }\end{array}$} & 0.0104 & 0.0122 & -0.00181 \\
\hline & & $(0.0143)$ & $(0.0130)$ & $(0.00295)$ \\
\hline \multirow[t]{2}{*}{ Infrastructure availability/use } & \multirow{2}{*}{$\begin{array}{l}\text { Broadband penetration } \\
\text { (per } 10 \text { inhabitants) }\end{array}$} & 0.0178 & -0.103 & $0.121^{* * *}$ \\
\hline & & $(0.131)$ & $(0.130)$ & $(0.0334)$ \\
\hline \multirow[t]{9}{*}{ Digital skills } & \multirow{2}{*}{$\begin{array}{l}\text { Skills readiness } \\
\text { (Index, 1-7) }\end{array}$} & $0.617^{\star *}$ & $0.564^{* *}$ & 0.0533 \\
\hline & & $(0.284)$ & $(0.271)$ & $(0.0589)$ \\
\hline & \multirow[t]{2}{*}{ Post 2017} & $2.532^{\star \star \star}$ & $1.248^{\star * *}$ & $1.284^{* \star *}$ \\
\hline & & $(0.411)$ & $(0.387)$ & $(0.0687)$ \\
\hline & Time FE & Yes & Yes & Yes \\
\hline & \multirow[t]{2}{*}{ Constant } & $-21.47^{\star * *}$ & $-16.70^{* * *}$ & $-4.768^{\star * *}$ \\
\hline & & $(3.600)$ & (3.491) & $(0.746)$ \\
\hline & Observations & 208 & 208 & 208 \\
\hline & R-squared & 0.820 & 0.777 & 0.832 \\
\hline
\end{tabular}

Note: Dependent variables are total traffic (logged), average traffic (logged) and number of platforms (logged) per country year and sector. Robust standard errors in parentheses.

Source: OECD calculations with data from Semrush and Crunchbase. 
Table B.2. Platform traffic and entry and platform characteristics

\begin{tabular}{|c|c|c|c|c|c|c|c|c|c|c|c|}
\hline & (1) & $(2)$ & $(3)$ & $(4)$ & (5) & (6) & (7) & (8) & (9) & $(10)$ & $(11)$ \\
\hline \multirow[t]{2}{*}{ Digital (5) / Physical (1) } & $-0.106^{* * *}$ & $-0.106^{\star * \star}$ & $0.0729^{\star * \star}$ & $0.166^{\star * *}$ & & & & & & $0.0765^{\star * *}$ & $0.0132^{* \star \star}$ \\
\hline & $(0.0178)$ & $(0.0156)$ & $(0.0268)$ & $(0.0221)$ & & & & & & $(0.0269)$ & $(0.00196)$ \\
\hline \multirow[t]{2}{*}{ Review Heavy (5) / Light (1) } & $0.117^{* \star *}$ & $0.103^{* * *}$ & $0.103^{* \star *}$ & & $0.223^{\star \star *}$ & & & & & $0.0991^{* * *}$ & $0.00728^{* \star \star}$ \\
\hline & $(0.0286)$ & $(0.0260)$ & $(0.0242)$ & & $(0.0192)$ & & & & & $(0.0246)$ & $(0.00131)$ \\
\hline \multirow[t]{2}{*}{ Capital (5) / Labour (1) } & $0.173^{\star \star \star}$ & $0.146^{\star \star \star}$ & $0.134^{*}$ & & & $0.114^{*}$ & & & & $0.132^{*}$ & $0.00662^{*}$ \\
\hline & $(0.0557)$ & $(0.0429)$ & $(0.0701)$ & & & $(0.0580)$ & & & & $(0.0693)$ & $(0.00355)$ \\
\hline \multirow[t]{2}{*}{ Aggregator (5) /Disruptor (1) } & $-0.0421^{* *}$ & $-0.0310^{* *}$ & -0.0295 & & & & -0.0121 & & & $-0.0372^{*}$ & $0.00461^{* \star}$ \\
\hline & $(0.0173)$ & $(0.0140)$ & $(0.0191)$ & & & & $(0.0177)$ & & & $(0.0195)$ & $(0.00187)$ \\
\hline International (43)/Local (1)a & $(0.00916)$ & $(0.0148)$ & $(0.0133)$ & & & & & $(0.0128)$ & & $(0.0131)$ & $(0.0171)$ \\
\hline \multirow[t]{2}{*}{ Diverse (1) / Specialized (0) } & $2.105^{\star * \star}$ & $1.808^{\star * \star}$ & $1.720^{\star \star \star}$ & & & & & & $2.999^{\star * *}$ & $1.732^{* \star *}$ & $0.183^{\star * \star}$ \\
\hline & $(0.202)$ & $(0.247)$ & $(0.220)$ & & & & & & $(0.234)$ & $(0.219)$ & $(0.0178)$ \\
\hline \multirow[t]{2}{*}{ Concentration (CR8) } & $-9.364^{* \star *}$ & $-4.019^{\star \star *}$ & $-4.455^{\star \star \star}$ & & & & & & & $-1.702^{* * *}$ & $-0.127^{\star}$ \\
\hline & (1.778) & $(1.157)$ & $(0.777)$ & & & & & & & $(0.342)$ & $(0.0750)$ \\
\hline Country-year FE & & $x$ & $x$ & $x$ & $x$ & $x$ & $x$ & $x$ & $x$ & & $x$ \\
\hline Sector FE & & & $x$ & $x$ & $x$ & $x$ & $x$ & $x$ & $x$ & & $x$ \\
\hline Co-Sec-Year FE & & & & & & & & & & $\mathrm{x}$ & \\
\hline R-squared & 0.181 & 0.266 & 0.282 & 0.163 & 0.168 & 0.162 & 0.162 & 0.266 & 0.190 & 0.310 & 0.296 \\
\hline
\end{tabular}

Note: Dependent variable is platform traffic (logged) in columns (1)-(10) and entry in column (11). Standard errors clustered at the country level in parenthesis. Column (1) includes country characteristics and a dummy for the period post 2017. The measure of turnover is CR8, the traffic share of the top 8 firms.. Diverse platforms are those operating in two or three areas of activity and specialised platforms are those operating in one area of activity. ${ }^{\text {a }}$ In columns (1)-(10), the level of intenationalisation is a continuous variable reflecting the number of countries (from 1 to 43 ) the platform operates on and in column (11) it is a dummy variable equal to 1 if the platform operates in 5 or more countries and zero otherwise

Source: Estimations by OECD with data from Semrush and Crunchbase. 
Table B.3. Structural policies and country-level traffic

\begin{tabular}{|c|c|c|c|c|c|c|c|c|c|c|c|}
\hline \multicolumn{4}{|c|}{ Broad institutional environment } & \multicolumn{4}{|c|}{$\begin{array}{l}\text { Product market regulation } \\
\end{array}$} & \multicolumn{4}{|c|}{ Digital services specific regulation } \\
\hline $\begin{array}{l}\text { Dependent } \\
\text { variables: }\end{array}$ & $\begin{array}{r}\text { Total } \\
\text { Traffic }\end{array}$ & $\begin{array}{r}\text { Average traffic } \\
\text { per platform }\end{array}$ & $\begin{array}{r}\text { Number of } \\
\text { Platforms }\end{array}$ & Dependent variables: & $\begin{array}{r}\text { Total } \\
\text { Traffic }\end{array}$ & $\begin{array}{l}\text { Average } \\
\text { traffic per } \\
\text { platform }\end{array}$ & $\begin{array}{r}\text { Number of } \\
\text { Platforms }\end{array}$ & $\begin{array}{r}\text { Dependent } \\
\text { variables: }\end{array}$ & $\begin{array}{r}\text { Total } \\
\text { Traffic }\end{array}$ & $\begin{array}{l}\text { Average } \\
\text { traffic per } \\
\text { platform }\end{array}$ & $\begin{array}{l}\text { Number of } \\
\text { Platforms }\end{array}$ \\
\hline \multirow{2}{*}{$\begin{array}{l}\text { Rule of law (WB } \\
\text { indicator) }\end{array}$} & $0.649^{\star \star *}$ & $0.441^{* *}$ & $0.208^{\star \star *}$ & \multirow{2}{*}{$\begin{array}{ll}\text { PMR } & \text { (Overall } \\
\text { indicator) } & \end{array}$} & -0.352 & -0.270 & -0.0817 & \multirow[t]{2}{*}{ DSTRI (Full) } & -2.003 & -2.810 & $0.807^{*}$ \\
\hline & $(0.206)$ & $(0.186)$ & $(0.0481)$ & & $(0.252)$ & $(0.220)$ & $(0.0669)$ & & $(2.022)$ & $(1.905)$ & $(0.484)$ \\
\hline Obs. & 208 & 208 & 208 & Obs. & 194 & 194 & 194 & Obs. & 208 & 208 & 208 \\
\hline R squared & 0.829 & 0.783 & 0.847 & R squared & 0.841 & 0.802 & 0.822 & R squared & 0.821 & 0.781 & 0.835 \\
\hline \multirow{2}{*}{$\begin{array}{l}\text { Control of corruption } \\
\text { (WB indicator) }\end{array}$} & $0.547^{\star \star \star}$ & $0.341^{* *}$ & $0.207^{\star \star *}$ & \multirow{2}{*}{$\begin{array}{l}\text { Administrative } \\
\text { burden on start-ups }\end{array}$} & -0.0666 & -0.0724 & 0.00578 & \multirow{2}{*}{$\begin{array}{l}\text { Cross border data } \\
\text { portability }(1-6)\end{array}$} & $0.449^{\star \star \star}$ & $0.436^{\star * *}$ & 0.0130 \\
\hline & $(0.181)$ & $(0.161)$ & $(0.0405)$ & & $(0.110)$ & $(0.0980)$ & $(0.0277)$ & & $(0.118)$ & $(0.106)$ & $(0.0331)$ \\
\hline Obs. & 208 & 208 & 208 & Obs. & 194 & 194 & 194 & Obs. & 208 & 208 & 208 \\
\hline R squared & 0.829 & 0.782 & 0.853 & R squared & 0.839 & 0.801 & 0.821 & R squared & 0.833 & 0.795 & 0.832 \\
\hline \multirow{2}{*}{$\begin{array}{l}\text { Judicial } \\
\text { independence (1-7) }\end{array}$} & $0.293^{* *}$ & 0.152 & $0.142^{* * *}$ & \multirow{2}{*}{$\begin{array}{l}\text { Barriers in services \& } \\
\text { network sectors }\end{array}$} & $-0.413^{\star \star \star}$ & $-0.308^{* *}$ & $-0.104^{\star * \star}$ & \multirow[t]{2}{*}{ PMR E-comm. } & -0.131 & -0.0168 & $-0.114^{* * *}$ \\
\hline & $(0.113)$ & $(0.105)$ & $(0.0248)$ & & $(0.139)$ & $(0.133)$ & $(0.0324)$ & & $(0.112)$ & $(0.108)$ & $(0.0333)$ \\
\hline Obs. & 208 & 208 & 208 & Observations & 194 & 194 & 194 & Obs. & 194 & 194 & 194 \\
\hline R squared & 0.826 & 0.780 & 0.857 & R squared & 0.844 & 0.805 & 0.827 & R squared & 0.840 & 0.801 & 0.833 \\
\hline \multirow[t]{2}{*}{$\begin{array}{l}\text { Effective law-making } \\
\text { bodies (1-7) }\end{array}$} & 0.0468 & -0.0115 & $0.0583^{*}$ & \multirow[t]{2}{*}{ OER Personal } & -0.0122 & 0.157 & $-0.170^{\star \star \star}$ & $\begin{array}{r}\text { State control over } \\
\text { the internet }\end{array}$ & $0.167^{* *}$ & 0.115 & $0.0516^{* * *}$ \\
\hline & $(0.116)$ & $(0.109)$ & $(0.0301)$ & & $(0.261)$ & $(0.266)$ & $(0.0533)$ & & $(0.0777)$ & $(0.0707)$ & $(0.0152)$ \\
\hline Obs. & 208 & 208 & 208 & Obs. & 108 & 108 & 108 & Obs. & 208 & 208 & 208 \\
\hline R squared & 0.820 & 0.777 & 0.836 & R squared & 0.882 & 0.829 & 0.932 & R squared & 0.823 & 0.780 & 0.838 \\
\hline $\begin{array}{l}\text { Efficient } \quad \text { legal } \\
\text { settling }\end{array}$ & -0.0799 & -0.146 & $0.0662^{* *}$ & \multirow[t]{2}{*}{ OER Professional } & 0.172 & 0.177 & -0.00440 & Comm. presence & $0.484^{* *}$ & $0.463^{* *}$ & 0.0208 \\
\hline disputes (1-7) & $(0.102)$ & $(0.0887)$ & $(0.0308)$ & & $(0.127)$ & $(0.121)$ & $(0.0291)$ & requirement & $(0.221)$ & $(0.197)$ & $(0.0510)$ \\
\hline Obs. & 208 & 208 & 208 & Obs. & 108 & 108 & 108 & Obs. & 208 & 208 & 208 \\
\hline R squared & 0.820 & 0.780 & 0.838 & R squared & 0.884 & 0.832 & 0.925 & R squared & 0.825 & 0.783 & 0.832 \\
\hline $\begin{array}{ll}\text { Efficient } & \text { legal } \\
\text { challenging } & \end{array}$ & -0.0577 & -0.159 & $0.102^{\star \star *}$ & \multirow[t]{2}{*}{ PMR Retail } & -0.0797 & -0.0404 & $-0.0393^{*}$ & \multirow[t]{2}{*}{$\begin{array}{l}\text { GDPR } \\
\text { implemented (1-0) }\end{array}$} & $0.530^{* *}$ & $0.467^{\star *}$ & 0.0632 \\
\hline reg. (1-7) & $(0.124)$ & $(0.109)$ & $(0.0350)$ & & $(0.0956)$ & $(0.0867)$ & $(0.0229)$ & & $(0.231)$ & $(0.221)$ & $(0.0734)$ \\
\hline Obs. & 208 & 208 & 208 & Obs. & 194 & 194 & 194 & Obs. & 208 & 208 & 208 \\
\hline
\end{tabular}


54 | ECO/CPE/WP1(2020)6

\begin{tabular}{|c|c|c|c|c|c|c|c|c|c|c|c|}
\hline R squared & 0.820 & 0.779 & 0.843 & R squared & 0.839 & 0.801 & 0.823 & R squared & 0.823 & 0.781 & 0.833 \\
\hline Cost to enforce & 0.00913 & 0.00291 & $0.00622^{* *}$ & \multirow[t]{2}{*}{ EP (regular) Ind/Coll } & -0.234 & -0.147 & $-0.0872^{\star *}$ & & & & \\
\hline contracts (1-7) & $(0.0105)$ & $(0.00987)$ & $(0.00247)$ & & -0.163 & -0.148 & -0.036 & & & & \\
\hline Obs. & 208 & 208 & 208 & Obs. & 208 & 208 & 208 & & & & \\
\hline \multirow{2}{*}{$\begin{array}{ll}\text { IP protection } & (7 \\
\text { more) } & \end{array}$} & $0.318^{*}$ & 0.194 & $0.124^{* * *}$ & \multirow{2}{*}{ EP (temporary) } & 0.0894 & $0.119^{*}$ & $-0.0295^{\star \star}$ & & & & \\
\hline & $(0.179)$ & $(0.157)$ & $(0.0468)$ & & -0.0672 & -0.0629 & -0.0143 & & & & \\
\hline Obs. & 208 & 208 & 208 & Obs. & 208 & 208 & 208 & & & & \\
\hline \multirow[t]{2}{*}{ Laws rel. ICTs (1-7) } & -0.0405 & -0.178 & $0.137^{\star *}$ & & & & & & & & \\
\hline & $(0.250)$ & $(0.223)$ & $(0.0562)$ & & & & & & & & \\
\hline Obs. & 208 & 208 & 208 & & & & & & & & \\
\hline R squared & 0.820 & 0.778 & 0.838 & & & & & & & & \\
\hline
\end{tabular}

Note: All regressions include the country characteristic set out in Section 4 as well as time fixed effects. Estimation of equation (3): $\ln \left(\right.$ dependent $_{\text {var }}$ ept $)=\beta_{1}$ Characteristics $_{c, t}+\beta_{2}$ Policy $_{c}+$ $\theta_{t}+\epsilon_{t, c}$ with each policy in turn. Robust standard errors in parentheses.

Source: Estimations by OECD with data from Semrush and Crunchbase. 
Table B.4. Platform traffic and concentration

\begin{tabular}{l|r|r|r}
\hline & \multicolumn{1}{|c|}{$(1)$} & \multicolumn{1}{c}{$(2)$} & \multicolumn{1}{c}{$(3)$} \\
\hline Concentration (CR8) & $-4.661^{* * *}$ & & \\
\hline Concentration (CR4) & $(0.878)$ & & \\
\hline & & $-1.920^{* * *}$ & \\
\hline Reshuffling at the top & & $(0.371)$ & \\
\hline & & & $0.495^{\star *}$ \\
\hline Platform characteristics & $\mathrm{x}$ & $\mathrm{x}$ & $(0.228)$ \\
\hline Sector FE & $\mathrm{x}$ & $\mathrm{x}$ & $\mathrm{x}$ \\
\hline Co-Year FE & $\mathrm{x}$ & $\mathrm{x}$ & $\mathrm{x}$ \\
\hline Observations & 58,046 & 58,046 & 55,304 \\
\hline R-squared & 0.393 & 0.393 & 0.393 \\
\hline
\end{tabular}

Note: Dependent variable is platform traffic (logged). All regressions include platform characteristics. Concentration is measured, respectively, by the share of traffic of the top 8 firms (CR8), the share of traffic of the top 4 firms (CR4), and the degree of reshuffling in the ranking of the top 8 from the year before (reshuffling at the top).

Source: Estimations by OECD with data from Semrush and Crunchbase. 